Article

\title{
Investigating the Antiparasitic Potential of the Marine Sesquiterpene Avarone, Its Reduced Form Avarol, and the Novel Semisynthetic Thiazinoquinone Analogue Thiazoavarone
}

\author{
Concetta Imperatore ${ }^{1,2,+} \mathbb{D}^{\mathbb{D}}$, Roberto Gimmelli ${ }^{3,+}$, , Marco Persico ${ }^{1,2,+}$, Marcello Casertano ${ }^{1,2}{ }^{(\mathbb{D}}$, \\ Alessandra Guidi ${ }^{3}$, Fulvio Saccoccia ${ }^{3}$, Giovina Ruberti ${ }^{3}{ }^{-}$, Paolo Luciano ${ }^{1}$, Anna Aiello ${ }^{1,2}$,

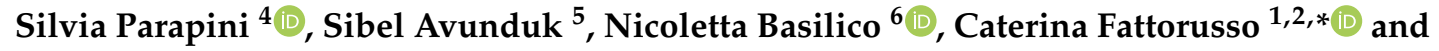 \\ Marialuisa Menna ${ }^{1,2, *(\mathbb{D})}$ \\ 1 The NeaNat Group, Department of Pharmacy, University of Naples “Federico II”, Via D. Montesano 49, \\ 80131 Napoli, Italy; cimperat@unina.it (C.I.); marco.persico@unina.it (M.P.); \\ marcello.casertano@unina.it (M.C.); pluciano@unina.it (P.L.); aiello@unina.it (A.A.) \\ 2 Italian Malaria Network, Centro Interuniversitario di Ricerche Sulla Malaria (CIRM), Department of \\ Pharmacy, University of Naples "Federico II", Via D. Montesano 49, 80131 Napoli, Italy \\ 3 Institute of Biochemistry and Cell Biology, National Research Council, Campus A. Buzzati-Traverso, Via E. \\ Ramarini, 32, 00015 Monterotondo (Roma), Italy; roberto.gimmelli@ibbc.cnr.it (R.G.); \\ alessandra.guidi@ibbc.cnr.it (A.G.); fulvio.saccoccia@ibbc.cnr.it (F.S.); giovina.ruberti@cnr.it (G.R.) \\ 4 Dipartimento di Scienze Biomediche per la Salute, Università di Milano, Via Pascal 36, 20133 Milan, Italy; \\ silvia.parapini@unimi.it \\ 5 Department Vocational School of Medicinal Health Services, Mugla University, 48187 Mugla, Turkey; \\ sibelavunduk@mu.edu.tr \\ 6 Dipartimento di Scienze Biomediche, Chirurgiche e Odontoiatriche, Università di Milano, Via Pascal 36, \\ 20133 Milan, Italy; nicoletta.basilico@unimi.it \\ * Correspondence: caterina.fattorusso@unina.it (C.F.); mlmenna@unina.it (M.M.); \\ Tel.: +39081678544 (C.F.); +39081678518 (M.M.) \\ + These authors equally contributed.
}

Received: 9 January 2020; Accepted: 11 February 2020; Published: 14 February 2020

\begin{abstract}
The chemical analysis of the sponge Dysidea avara afforded the known sesquiterpene quinone avarone, along with its reduced form avarol. To further explore the role of the thiazinoquinone scaffold as an antiplasmodial, antileishmanial and antischistosomal agent, we converted the quinone avarone into the thiazinoquinone derivative thiazoavarone. The semisynthetic compound, as well as the natural metabolites avarone and avarol, were pharmacologically investigated in order to assess their antiparasitic properties against sexual and asexual stages of Plasmodium falciparum, larval and adult developmental stages of Schistosoma mansoni (eggs included), and also against promastigotes and amastigotes of Leishmania infantum and Leishmania tropica. Furthermore, in depth computational studies including density functional theory (DFT) calculations were performed. A toxic semiquinone radical species which can be produced starting both from quinone- and hydroquinone-based compounds could mediate the anti-parasitic effects of the tested compounds.
\end{abstract}

Keywords: Dysidea avara; avarone/avarol; redox-active compounds; quinones and hydroquinones; dioxothiazinoquinone; Schistosoma mansoni; Plasmodium falciparum; Leishmania spp.; 3D-SAR analysis; DFT studies 


\section{Introduction}

Malaria and neglected tropical diseases (NTDs), a group of parasitic, bacterial, and viral infectious diseases (i.e., Schistosoma spp., Leishmania spp.), still have high morbidity and/or mortality rates worldwide. They affect more than one billion people and cause chronic illness, physical disability and/or deaths, especially in children and women of childbearing age, mostly in developing countries where they represent a serious hurdle to social and economic growth as well as a health problem $[1,2]$. Parasites belonging to different species can affect humans and animals concurrently, a phenomenon referred to as multiparasitism, which poses additional diagnostic and therapeutic challenges [3]. The therapeutic strategies for malaria and NTDs are very limited; drug-resistance phenomena, toxicity profiles and drug administration procedures of the few available chemical entities are still challenging. In this view, a research aimed to discover new chemicals active against several parasites is crucial and the marine environment may be an important resource [4,5]. In order to cope with all the reported drawbacks and to limit the costs of the development of brand-new pharmaceutical strategies, several effective antimalarial drugs should be considered for the treatment of other underfunded parasitic diseases. For example, artemisinin and its derivatives, a potent class of antimalarial agents, have been proved to be beneficial for other infectious diseases such as schistosomiasis and leishmaniasis [6]. Furthermore, histone deacetylases (HDAC) inhibitors have been shown to have activity both against some Plasmodium species as well as Leishmania and Schistosoma parasites [7]. Importantly, the blood parasites, Plasmodium and Schistosoma, both feeding on human hemoglobin, can detoxify the free heme groups through the synthesis of insoluble hemozoin pigments [8]. The interference with hemozoin formation featured an important antischistosomal mechanism of action showed by the antimalarial quinine and quinidine [9].

In the frame of our research for new anti-parasitic chemical entities, we recently identified the thiazinoquinone scaffold as a novel chemotype active against both Plasmodium falciparum and Schistosoma mansoni [10-14]. We developed this scaffold by creating of a chemical library of thiazinoquinone derivatives designed on the model of aplidinones, natural products isolated from a marine invertebrate (Figure 1). Many compounds exhibited in vitro antiplasmodial activities against the D10 and W2 strains of $P$. falciparum $[11,13]$ with $\mathrm{IC}_{50}$ in the low micromolar range. Through an integrated experimental (cyclic voltammetry) and theoretical approach, we demonstrated that the antiplasmodial and anticancer activity of a series of thiazinoquinone compounds was not related to their two electrons redox potential $[11,12]$. In particular, the antiplasmodial activity was found to depend on the ability of the compound to generate a semiquinone radical species able to form a stable adduct with heme [11]. This was later supported by the design and synthesis of other sets of new thiazinoquinone derivatives, indicating that the activity was related to the ability to form a specific semiquinone radical, and to the ability of this latter to transfer the radical by and hydrogen-radical shift to the R substituent [13]. In addition, several important SARs were obtained. First, the thiazinoquinone moiety was ascertained to be necessary for the antiplasmodial activity, since the corresponding quinone derivatives (e.g., derivatives lacking the 1,1-dioxothiazine moiety) were inactive. Second, the regiochemistry of the heterocyclic ring with respect to the substituents (a methoxyl group and an alkyl chain) on the quinone ring was revealed as crucial for the activity. Third, the nature and shape of the $\mathrm{R}^{\prime}$ substituent were able to affect compound potency and selectivity. 


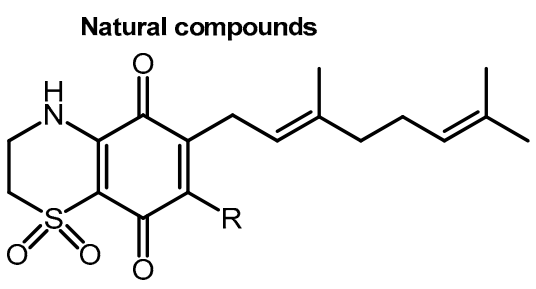

$\mathrm{R}=-\mathrm{OMe} ;$ Aplidinone $\mathrm{A}$

$\mathrm{R}=-\mathrm{NH}_{2} ;$ Aplidinone $\mathrm{B}$

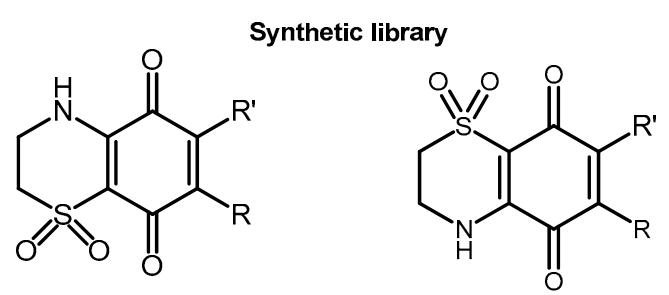

$\mathrm{R}=-\mathrm{OMe} ; \mathrm{R}^{\prime}=-\mathrm{CH}_{2} \mathrm{CH}_{3}$

$\mathrm{R}=-\mathrm{OMe} ; \mathrm{R}^{\prime}=\left(\mathrm{CH}_{2}\right)_{7} \mathrm{CH}_{3}$

$\mathrm{R}=-\mathrm{OMe} ; \mathrm{R}^{\prime}=\left(\mathrm{CH}_{2}\right)_{13} \mathrm{CH}_{3}$

$\mathrm{R}=-\mathrm{OMe} ; \mathrm{R}^{\prime}=\left(\mathrm{CH}_{2}\right)_{3} \mathrm{CH}_{3}$

$\mathrm{R}=-\mathrm{OMe} ; \quad \mathrm{R}^{\prime}=-\mathrm{CH}_{2} \mathrm{CH}\left(\mathrm{CH}_{3}\right)_{2}$

$\mathrm{R}=-\mathrm{OMe} ; \mathrm{R}^{\prime}=-\mathrm{CH}_{2} \mathrm{C}_{6} \mathrm{H}_{11}$

$\mathrm{R}=-\mathrm{OMe} ; \mathrm{R}^{\prime}=-\mathrm{CH}_{2} \mathrm{C}_{6} \mathrm{H}_{5}$

$\mathrm{R}=-\mathrm{NHCOC}\left(\mathrm{CH}_{3}\right)_{3} ; \mathrm{R}^{\prime}=-\mathrm{CH}_{2} \mathrm{CH}_{3}$

$\mathrm{R}=-\mathrm{NHCOC}\left(\mathrm{CH}_{3}\right)_{3} ; \mathrm{R}^{\prime}=-\left(\mathrm{CH}_{2}\right)_{4} \mathrm{CH}_{3}$

$\mathrm{R}=-\mathrm{NHCOC}\left(\mathrm{CH}_{3}\right)_{3} ; \mathrm{R}^{\prime}=-\left(\mathrm{CH}_{2}\right)_{10} \mathrm{CH}_{3}$

Figure 1. Structures of aplidinones A, B and of thiazinoquinone derivatives.

Successively, we selected both some of the developed methoxy thiazinoquinones, and some ad hoc synthesized new derivatives with the aim of investigating the antischistosomal properties of this chemical scaffold. Compounds were thus tested against larval stage, adult worm couples and eggs of the platyhelminth S. mansoni [14]. Many of the tested molecules resulted active and, interestingly, as observed for the antiplasmodial activity, the effects against $S$. mansoni strongly depended on the regiochemistry of the heterocyclic ring, and from the nature and/or steric hindrance of the $\mathrm{R}^{\prime}$ substituent. Computational studies indicated that semiquinone radical species could be involved also in the mode of action against S. mansoni impairing the redox equilibrium within the parasite. Importantly, the $\mathrm{R}^{\prime}$ properties can affect both the pharmacodynamics and pharmacokinetics of the compounds [14].

In the course of a systematic chemical study of the macroflora and macrofauna of the coastal area of Turkey in the İzmir Bay (Aegean Sea), as a part of our ongoing search for bioactive marine-derived metabolites as leads for drug discovery [15-20], we isolated from the sponge Dysidea avara (Schmidt, 1862) the known sesquiterpene quinone avarone (1), along with its reduced form avarol (3, Figure 2) [21-23]. A wide range of pharmacological properties have been reported for the redox couple avarone (1) and avarol (3) including anti-tumor [24-26], anti-inflammatory [27-29], anti-mutagenic [30], anti-bacterial [31,32], anti-viral [33,34], anti-oxidant [23,35], anti-platelet [28], anti-psoriatic [36] and anti-biofouling [37,38] activities. Pharmacological studies on synthetic and semisynthetic derivatives of avarone have been previously reported, too [23,39-41]. Based on the above described extensive exploration of the thiazinoquinone scaffold as antiplasmodial and antischistosomal agent $[11,13,14]$, we used the quinone avarone (1) as chemical starting point to obtain the semisynthetic thiazinoquinone derivative, thiazoavarone (2, Figure 2). Compound 2, as well as the natural metabolites 1 and 3, were investigated in order to evaluate their in vitro activity against: (i) asexual stages of D10 and W2 strains and stage $\mathrm{V}$ gametocytes of P. falciparum, (ii) egg production, larval and adult stages of S. mansoni, (iii) promastigote and amastigote stages of Leishmania infantum and Leishmania tropica. Computational studies, including density functional theory (DFT) calculations, were performed in order to analyze the conformational and redox properties of the two natural metabolites (1 and $\mathbf{3})$, as well as those of the novel semisynthetic analogue 2 .

The obtained results shed light on the putative mechanism of action of the quinone/hydroquinone/thiazinoquinone compounds corroborating the hypothesis that their antiparasitic activity is related to the formation of a toxic semiquinone radical species. Noteworthy, thiazoavarone 2 resulted the most potent antimalarial thiazinoquinone developed by us, highlighting the important role for the activity played by the substituent of the 1,1-dioxo-1,4-thiazine ring. 

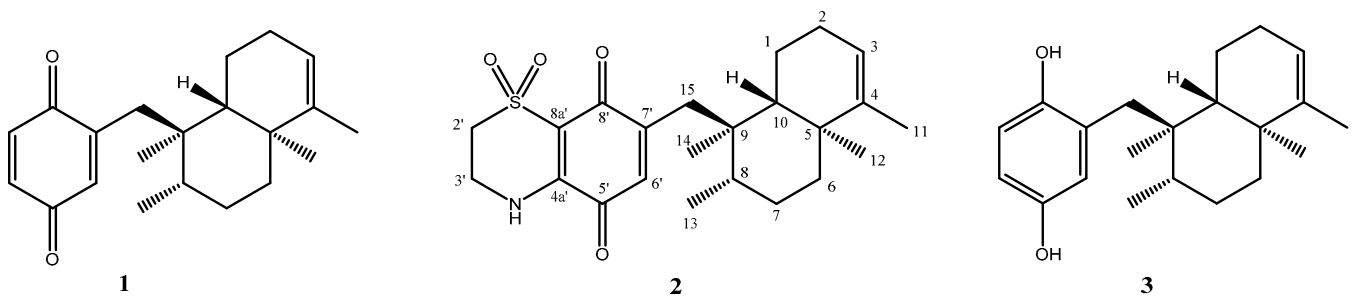

Figure 2. Structure of avarone (1), the semisynthetic thiazoavarone (2) and avarol (3).

\section{Results and Discussion}

\subsection{Chemistry}

Avarone (1) and avarol (3) were isolated from the sponge D. avara and purified according to the previously described procedures [21-23]. They were easily identified by comparison of their spectroscopic properties ( ${ }^{1} \mathrm{H}$ and ${ }^{13} \mathrm{C}$ NMR, HRESI-MS) with those reported in literature [21-23].

Thiazoavarone (2) was prepared as reported in Scheme 1. A portion of avarone was dissolved in a solution of $\mathrm{CH}_{3} \mathrm{CN} / \mathrm{EtOH}(1: 1)$ and then hypotaurine and a catalytic amount of salcomine in portion were added. The mixture was stirred for $48 \mathrm{~h}$ at room temperature and then was extracted with diethyl ether. The crude material was purified by HPLC on a reverse phase column (Luna $3 \mu \mathrm{m}$, $150 \times 3.00 \mathrm{~mm})\left(\mathrm{MeOH} / \mathrm{H}_{2} \mathrm{O} 75: 25 \mathrm{v} / \mathrm{v} \%\right)$ to afford the pure compound 2 . The nucleophilic addition reaction is regioselective in unsymmetrical quinones but generally leads to the formation of both regioisomers one of which is obtained in large excess with respect to the other. In the case of avarone, a single isomeric product, thiazoavarone 2, has formed, as determined by MS and NMR spectroscopy; this could be reasonably due to the high steric hindrance of the heavy sesquiterpene moiety.
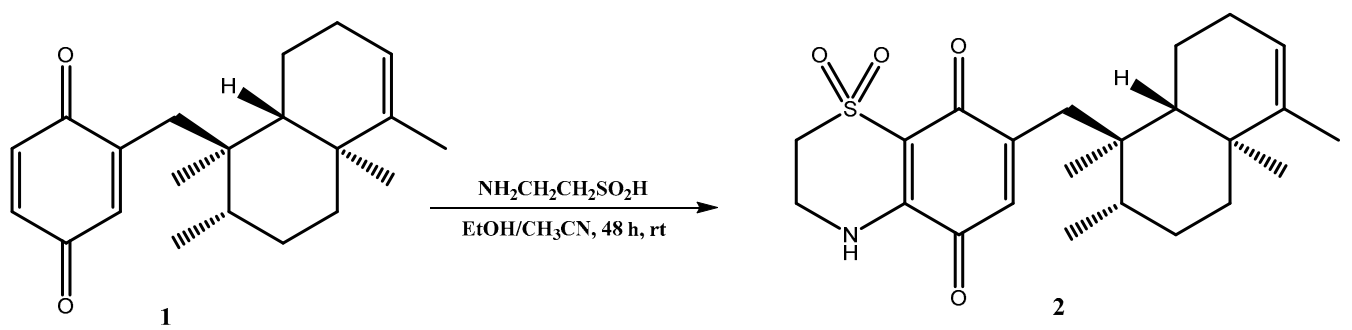

Scheme 1. Coupling of avarone (1) with hypotaurine via nucleophilic addition reaction.

Compound 2, obtained as yellow powder, $[\alpha]_{\mathrm{D}}{ }^{25}=+19.2$ (c 0.004, MeOH), had a molecular formula of $\mathrm{C}_{23} \mathrm{H}_{31} \mathrm{NO}_{4} \mathrm{~S}$ as determined by the HRESI MS ion at $\mathrm{m} / \mathrm{z} \mathrm{C}_{23} \mathrm{H}_{31} \mathrm{NO}_{4} \mathrm{SNa}[\mathrm{M}+\mathrm{Na}]^{+} 440.1865$ (calculated value: 440.1866). Molecular formula obtained from MS and a first survey of the 1D NMR spectra of $\mathbf{2}\left(\mathrm{CDCl}_{3}\right)$ and the comparison with those of the known avarone $\mathbf{1}$ quickly allowed us to hypothesize that the condensation reaction with hypotaurine has occurred. ${ }^{1} \mathrm{H}$ and ${ }^{13} \mathrm{C}$ NMR data of 2 indicated the same decalin ring system of $\mathbf{1}$, and the only difference between the two compounds is in the quinonic portion. Indeed, ${ }^{1} \mathrm{H}$ NMR spectrum of 2 lacked the signals at $\delta_{\mathrm{H}} 6.51$ and 6.71, whereas contained a quite deshielded methylene signals $\left(\delta_{\mathrm{H}} 3.30\right.$ and 4.05$)$, resonating as two multiplets and each integrating for two protons. Likewise, the ${ }^{13} \mathrm{C}$ spectrum of 2 contained two additional methilene carbon resonances at $\delta_{C} 39.8$ and at $\delta_{C} 48.8$ attributable to a nitrogen and sulfoxide-bearing carbons, respectively. The key HMBC cross-peaks (Figure 3$)$ from $\mathrm{H}-3^{\prime}$ to $\mathrm{C}-2^{\prime}\left(\delta_{\mathrm{C}} 48.8\right), \mathrm{C}-4 \mathrm{a}^{\prime}\left(\delta_{\mathrm{C}} 143.2\right)$, and from $\mathrm{H}-2^{\prime}$ to $\mathrm{C}-3^{\prime}\left(\delta_{\mathrm{C}} 39.8\right), \mathrm{C}-8 \mathrm{a}^{\prime}\left(\delta_{\mathrm{C}} 111.6\right)$, from $\mathrm{H}-6^{\prime}$ to $\mathrm{C}-4 \mathrm{a}^{\prime}\left(\delta_{\mathrm{C}} 143.2\right)$, and from H-15a and H-15b' to $C-8^{\prime}\left(\delta_{C} 177.1\right)$ indicated the regiochemistry of 2 . It should be noted that only one of possible regioisomer has been obtained. 


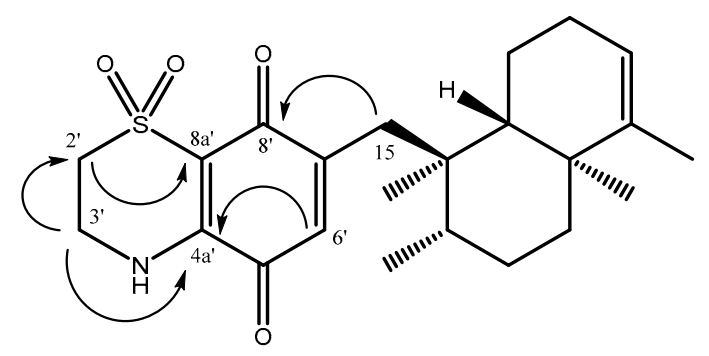

2

Figure 3. Key ${ }^{1} \mathrm{H}^{13} \mathrm{C}$ HMBC correlations of thiazoavarone (2).

Chemical shifts and coupling patterns of the all signals of 2 were assigned by aid of COSY, HSQC, and HMBC experiments (Table 1). Anyway, a purity higher than $99.8 \%$ has been determined by HPLC for compounds 1-3.

Table 1. ${ }^{1} \mathrm{H}(700 \mathrm{MHz})$ and ${ }^{13} \mathrm{C}(125 \mathrm{MHz})$ NMR data of thiazoavarone (2) in $\mathrm{CDCl}_{3}$.

\begin{tabular}{|c|c|c|c|c|c|}
\hline Pos. & $\delta_{C}$ & $\delta_{\mathrm{H}}$, mult. $(J$ in $\mathrm{Hz})$ & Pos. & $\delta_{C}$ & $\delta_{\mathrm{H}}$, mult. $(J$ in $\mathrm{Hz})$ \\
\hline $\mathbf{1}^{\prime}$ & - & - & 4 & 143.7 & - \\
\hline $2^{\prime}$ & 48.8 & $3.30, \mathrm{~m}$ & 5 & 38.3 & - \\
\hline $3^{\prime}$ & 39.8 & $4.05, \mathrm{~m}$ & 6 & 35.8 & $1.03^{\mathrm{a}}, 1.64^{\mathrm{a}}$ \\
\hline $4^{\prime}$ & - & 6.41 , br s & 7 & 27.3 & $1.38^{\mathrm{a}}$ \\
\hline $4 a^{\prime}$ & 143.2 & - & 8 & 37.1 & $1.25^{\mathrm{a}}$ \\
\hline $5^{\prime}$ & 179.3 & - & 9 & 43.7 & - \\
\hline $6^{\prime}$ & 131.8 & $6.50, \mathrm{~s}$ & 10 & 47.5 & $1.03^{\mathrm{a}}$ \\
\hline $7^{\prime}$ & 152.8 & - & 11 & 17.9 & $1.53, \mathrm{~s}$ \\
\hline $8^{\prime}$ & 177.1 & - & 12 & 20.0 & $0.99, \mathrm{~s}$ \\
\hline $8 a^{\prime}$ & 111.6 & - & 13 & 16.7 & $0.96, d,(6.2)$ \\
\hline 1 & 19.3 & $\begin{array}{c}1.50^{\mathrm{a}}, 1.85, \mathrm{dd},(6.7 \\
13.2)\end{array}$ & 14 & 17.7 & $0.85, \mathrm{~s}$ \\
\hline 2 & 26.3 & $1.93^{\mathrm{a}}, 2.04^{\mathrm{a}}$ & $15 a$ & & $2.50, \mathrm{~d},(13.1)$ \\
\hline 3 & 120.9 & 5.2, br s & $15 b$ & 35.6 & $2.70, d,(13.1)$ \\
\hline
\end{tabular}

\subsection{In Vitro Activity on P. falciparum and Cytotoxicity}

Avarone (1) and the semisynthetic 1,1-dioxo-1,4-thiazine analogue (2), as well as hydroquinone avarol (3) were tested for their in vitro antiplasmodial activity against asexual and sexual (gametocytes stage V) stages of P. falciparum (Table 2). A chloroquine-sensitive (CQ-S) D10 and a chloroquine-resistant (CQ-R) W2 strains were used to determine the $\mathrm{IC}_{50}$ against asexual stage of parasites. The most potent compound was thiazoavarone (2) with an $\mathrm{IC}_{50}$ value in the nanomolar range, higher than those exhibited by the previously identified synthetic lead [13]. The high potency of the thiazinoquinone 2, specifically on the chloroquine-resistant strain W2 and compared with avarone (1), lacking the heterocyclic moiety, confirmed once again the high potential of the thiazinoquinone scaffold for development of new antimalarial hits. Interestingly, both natural compounds $\mathbf{1}$ and $\mathbf{3}$ also exhibited a remarkable effect against sensitive and resistant $P$. falciparum strains, showing no cross-resistance with chloroquine (see Table 2). In particular, the reduced hydroquinone form (avarol, 3) resulted significantly more active than the oxidized quinone form (avarone, $\mathbf{1}$ ).

The evaluation of the effects of compounds 1-3 on Pf gametocytes stage $\mathrm{V}$, the sexual stage circulating in the bloodstream, was performed in order to evaluate their transmission blocking potential. As evidenced in Table 2, all the three compounds resulted less active against the gametocytes with respect to the parasite asexual stage; this finding is not unexpected since most of the current antimalarial drugs have no effect on the late stage of gametocytes. Avarol (3) resulted the most potent 
in the series against $P f$ gametocytes stage $\mathrm{V}$ with an $\mathrm{IC}_{50}=9.30 \mu \mathrm{M}$, comparable to that of $\mathrm{OZ} 27$, a drug in clinical development $\left(\mathrm{IC}_{50}=6.4 \mu \mathrm{M}\right)$ [42].

Table 2. In vitro antimalarial activity against asexual $P$. falciparum parasites from D10 (CQ-sensitive) and W2 (CQ-resistant) strains ${ }^{\mathrm{a}}$ and against stage V P. falciparum gametocytes from a 3D7 transgenic line.

\begin{tabular}{cccc}
\hline Compounds & $\mathbf{D 1 0}(\boldsymbol{\mu M})^{\mathbf{b}}$ & $\mathbf{W} 2(\mu \mathbf{M})^{\mathbf{b}}$ & $\begin{array}{c}\text { Pf Gametocytes Stage V } \\
\left.\text { 3D7elo1-pfs16-CBG99 IC }_{\mathbf{5 0}}(\boldsymbol{\mu M})\right)^{\mathbf{b}}\end{array}$ \\
\hline Avarone (1) & $2.74 \pm 0.51$ & $2.09 \pm 0.52$ & $15.53 \pm 5.26$ \\
Thiazoavarone (2) & $0.38 \pm 0.15$ & $0.21 \pm 0.03$ & $15.01 \pm 3.19$ \\
Avarol (3) & $0.96 \pm 0.24$ & $1.10 \pm 0.15$ & $9.30 \pm 1.90$ \\
Methylene blue & - & - & $0.155 \pm 0.05$ \\
\hline
\end{tabular}

${ }^{\mathrm{a}}$ Chloroquine (CQ) has been used as positive control $\left(\mathrm{D} 10 \mathrm{IC}_{50}=0.04 \pm 0.01 ; \mathrm{W} 2 \mathrm{IC}_{50}=0.54 \pm 0.28\right) .{ }^{\mathrm{b}}$ The results are the mean $\pm \mathrm{SD}$ of $\mathrm{IC}_{50}$ of three independent experiments performed in duplicate.

Finally, we tested compounds 1-3 for their cytotoxic effects against two different human cell lines, microvascular endothelial (HMEC-1) and acute monocytic leukemia (THP-1) cells differentiated into macrophages; for each compound, we evaluated the selectivity index (SI, Table 2), namely the ratio between the $\mathrm{IC}_{50}$ on the human cells HMEC and that on the parasite strains (see Table 3). Thiazoavarone (2) exhibited a high toxicity against both mammalian cell lines, with $\mathrm{IC}_{50}$ in the low micromolar concentration range and, consequently, a very low SI. Avarone and avarol (1 and $\mathbf{3})$ were lowly and moderately cytotoxic, respectively (Table 3) but the hydroquinone 3 exhibited a better SI.

Table 3. $\mathrm{IC}_{50}$ against HMEC-1 (human microvascular endothelial cells) and THP-1 (human acute monocytic leukemia cells) and Selectivity Index (SI) of the compounds 1-3.

\begin{tabular}{|c|c|c|c|c|}
\hline \multirow{2}{*}{ Compounds } & \multirow{2}{*}{$\begin{array}{l}\text { HMEC-1 IC } \text { I }_{50} \\
(\mu \mathrm{M})^{\mathrm{a}, \mathrm{b}}\end{array}$} & \multirow{2}{*}{ THP-1 $\underset{a, c}{\mathrm{IC}_{50}}(\mu \mathrm{M})$} & \multicolumn{2}{|c|}{ SI $^{d}$} \\
\hline & & & D10 & W2 \\
\hline Avarone (1) & $62.19 \pm 1.98$ & $>100$ & 22.7 & 29.8 \\
\hline Thiazoavarone (2) & $3.31 \pm 1.53$ & 7.41 & 8.7 & 15.8 \\
\hline Avarol (3) & $36.85 \pm 5.79$ & 31.75 & 38.4 & 33.5 \\
\hline
\end{tabular}

${ }^{\mathrm{a}}$ Camptothecin has been used as positive control $\left(\mathrm{IC}_{50}(\mu \mathrm{M})=0.018 \pm 0.008\right.$ on HMEC-1). ${ }^{\mathrm{b}}$ Data are expressed as mean $\pm \mathrm{SD}$ of three different experiments performed in duplicate. ${ }^{c}$ Data are the mean of two different experiments in duplicate. ${ }^{\mathrm{d}} \mathrm{SI}=\mathrm{IC}_{50} \mathrm{HMEC}-1 / \mathrm{IC}_{50}$ P. falciparum strain.

\subsection{In vitro Activity on Leishmania Parasites}

To assess the antileishmanial activity of compounds 1-3 we tested them against promastigote stage of $L$. infantum and L. tropica responsible for visceral and cutaneous leishmaniasis, respectively. The results of this study are reported in Table 4 as $\mathrm{IC}_{50}$ values with the relevant selectivity indexes (SIs). Considering the couple avarone/avarol, we can notice that, as observed for the antiplasmodial effects, the reduced form (3) is substantially more potent than the oxidized form $\mathbf{1}$ on both investigated Leishmania parasites. This has been reported also for several antileishmanial naphthohydroquinones which resulted more active than the corresponding naphthoquinones [43]. Instead, the hydroquinone metabolite 3 and the thiazinoquinone 2 exhibited similar values of $\mathrm{IC}_{50}$ in the range of low micromolar; however, avarol (3) showed a significantly higher SI (see Table 4). Definitely, the above results displayed that introduction of the 1,1-dioxo-1,4-thiazine ring in the structure of avarone (1) to give thiazoavarone (2) meaningfully improves the antileishmanial activity, once again according to the antiplasmodial effects (see Tables 2 and 4).

In addition, compounds 1-3 were also investigated against intracellular amastigotes, the clinically relevant form of Leishmania. All compounds resulted from 2 to 4 -fold more active against amastigotes than promastigotes; the hydroquinone avarol 3 confirmed itself as a promising agent to be further investigated in efficacy and selectivity, presenting the lowest $\mathrm{IC}_{50}$ value in the series and a SI greater than 10 (Table 4) [44]. 
Table 4. Activity of compounds 1-3 against promastigote stage of L. infantum and L. tropica and against amastigote stage of L. infantum.

\begin{tabular}{|c|c|c|c|c|c|c|}
\hline Compounds & $\begin{array}{l}\text { L. infantum } \\
\mathrm{IC}_{50}(\mu \mathrm{M})^{\mathrm{a}}\end{array}$ & $S I_{p}{ }^{c}$ & $\begin{array}{l}\text { L. tropica } \\
\mathrm{IC}_{50}(\mu \mathrm{M})^{\mathrm{a}}\end{array}$ & $\mathrm{SI}_{\mathrm{p}}{ }^{\mathrm{c}}$ & $\begin{array}{l}\text { L. infantum } \\
\text { Amastigotes } \mathrm{IC}_{50}(\mu \mathrm{M}){ }^{\mathrm{b}}\end{array}$ & $\mathrm{SI}_{\mathrm{a}}{ }^{\mathrm{d}}$ \\
\hline Avarone (1) & $28.21 \pm 0.32$ & 2.2 & $20.28 \pm 3.56$ & 3.1 & 7.64 & 8.1 \\
\hline Thiazoavarone (2) & $8.78 \pm 0.26$ & 0.38 & $9.52 \pm 0.32$ & 0.35 & 4.99 & 0.67 \\
\hline Avarol (3) & $7.42 \pm 0.27$ & 5.0 & $7.08 \pm 1.91$ & 5.2 & 3.19 & 11.6 \\
\hline Amphotericin B & $0.20 \pm 0.03$ & & $0.17 \pm 0.04$ & & 0.189 & \\
\hline
\end{tabular}

${ }^{\mathrm{a}}$ Data are expressed as mean $\pm \mathrm{SD}$ of three different experiments performed in duplicate. ${ }^{\mathrm{b}}$ Data are the mean of two different experiments in triplicate. ${ }^{c} \mathrm{SI}_{\mathrm{p}}=\mathrm{IC}_{50} \mathrm{HMEC}-1 / \mathrm{IC}_{50}$ L. infantum (L. tropica) promastigotes. ${ }^{\mathrm{d}} \mathrm{SI}_{\mathrm{a}}=\mathrm{IC}_{50}$ HMEC-1/IC 50 L. infantum amastigotes.

\subsection{In Vitro Activity on S. mansoni}

Compounds 1-3 were tested against larval stage (schistosomula), adult worm couples and eggs of the platyhelminth S. mansoni. The most potent compound on schistosomula was thiazoavarone (2) with a $\mathrm{LC}_{50}$ value in the low micromolar range (Table 5). The natural compounds (1 and $\left.\mathbf{3}\right)$ showed comparable activity, with avarol (3) slightly more active than avarone (1), both showing a $\mathrm{LC}_{50}$ in the high micromolar range (Table 5). Therefore, the presence of a thiazine ring was proved to be very important for activity on schistosomula.

Table 5. Activity of compounds 1-3 against S. mansoni schistosomula.

\begin{tabular}{cc}
\hline Compounds & $\mathbf{L C}_{\mathbf{5 0}}(\boldsymbol{\mu M})^{\mathbf{a}}$ \\
\hline Avarone (1) & $42.77 \pm 1.90$ \\
Thiazoavarone (2) & $5.90 \pm 2.59$ \\
Avarol (3) & $33.97 \pm 5.52$ \\
\hline
\end{tabular}

${ }^{\mathrm{a}}$ Data are expressed as mean $\pm \mathrm{SD}$ of three different experiments.

All three compounds 1-3 were also very active on adult worm pairs at $50 \mu \mathrm{M}$ leading to parasites death 7 days after treatment (Figure 4). However, when used at lower concentration ( $20 \mu \mathrm{M})$, only avarol (3) strongly impaired parasites viability (only 20\% survival), while thiazoavarone (2) was poorly effective against the adult stage (Figure 4), despite its strong lethal effect on the larval stage (Table 5). These results suggest the possibility that the double lipid bilayer coating the adult worms, namely the tegument [45], can interfere with compound 2 uptake by adult parasites.
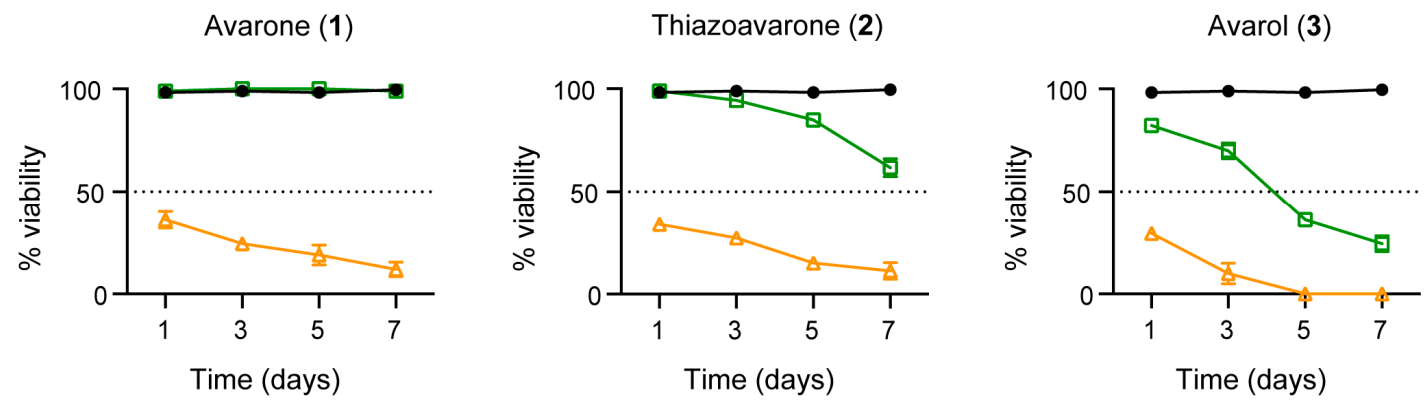

Figure 4. Compounds 1-3 impair adult S. mansoni viability. Worm pairs were incubated with DMSO (vehicle) (black circle) or the indicated compounds at $50 \mu \mathrm{M}$ (yellow triangle), or $20 \mu \mathrm{M}$ (green, square) as described in material and methods. Phenotype analysis was recorded for 7 days and \% viability represents the mean \pm SEM of three independent experiments.

In the process of drug discovery for schistosomiasis, strategy involving any impairment in egg production and/or development must also be taken into account. In fact, upon mating with males, mature S. mansoni adult females, residing in the mesenteric veins of the definitive host, can lay 
hundreds of eggs each day. The eggs secreted in stool or trapped in the liver respectively cause disease transmission and, as a result of inflammatory granulomas reactions, intestinal and hepato-splenic diseases [46]. Therefore, compounds 1-3 were also assayed against the in vitro laid eggs (IVLEs). The IVLEs produced in the first $48 \mathrm{~h}$ by $S$. mansoni pairs and treated for 3 days with vehicle or compounds 1-3 were classified by microscopic observation according to the Vogel and Prata staging system of egg maturation [47]. The thiazoavarone (2) resulted the most effective compound, impairing eggs maturation already at $5 \mu \mathrm{M}$ and resulting in undeveloped and severely damaged eggs at $20 \mu \mathrm{M}$ (Figure 5). Similar results were obtained with compounds $\mathbf{1}$ and 3 at $50 \mu \mathrm{M}$.

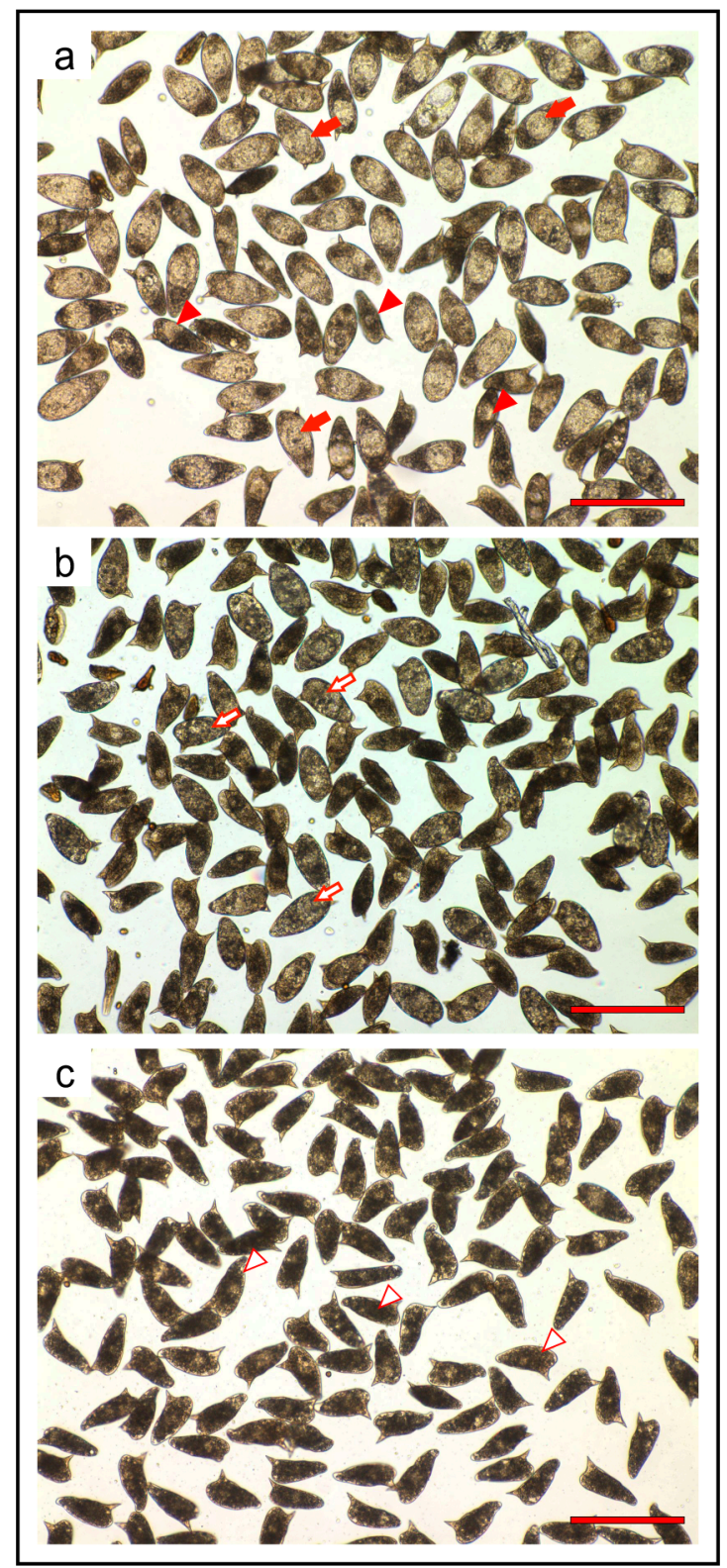

Figure 5. Thiazoavarone (2) impairs egg viability and maturation. Representative pictures of IVLEs treated with vehicle (DMSO) (a) or compound 2 at $5 \mu \mathrm{M}$ (b) and $20 \mu \mathrm{M}$ (c) for $72 \mathrm{~h}$. Filled red arrows indicate viable eggs at stages III-V (intermediate/developed); filled red triangle indicate viable eggs at stages I-II (immature); red-edged arrows indicate damaged eggs at stages III-V; red-edged triangle indicate damaged eggs at stages I-II. Bar, $200 \mu \mathrm{m}$. 


\subsection{Computational Studies and DFT Calculations}

To rationalize the observed SARs, the steric and electronic features of compounds 1-3 were investigated by means of computational studies, including conformational analysis and DFT calculations.

A systematic conformational search considering all rotatable bonds was applied to generate all possible conformations of the compounds, which were, then, subjected to molecular mechanic (MM) geometry optimization using the CFF force field and a distance dependent dielectric constant value of 80 (Discovery Studio 2017, BIOVIA, San Diego USA; see the experimental Section for details) [48]. The global minimum energy conformer (GM) was identified for each compound. All the generated conformers presented an energy difference from the $\mathrm{GM}\left(\Delta E_{\mathrm{GM}}\right) \leq 3 \mathrm{kcal} / \mathrm{mol}$. MM conformers were, then, subjected to density functional theory (DFT) calculations. In order to mimic an aqueous environment, all DFT calculations were performed using the conductor-like polarizable continuum model (C-PCM) as solvent model [49]. Moreover, to characterize every structure as minimum, a vibrational analysis was carried out (see the experimental Section for details). Fully optimized DFT conformers were classified into families according to the values of their torsion angles (Tables 6 and 7 and Table S1).

Results evidenced that compounds 1-3 present common conformational features, characterized by the electronic attraction between the hydrogen atoms of the first methylene group of the alkyl substituent and the nearby quinone oxygen, which limits the conformational freedom of $\mathrm{R}^{\prime}$ (Figure 6). Accordingly, the torsional angle $\tau 1$ showed just two sets of possible values $\left(\sim \pm 100^{\circ}\right.$; Tables 6 and 7 and Table S1), and for each of them the rigid sesquiterpene ring could assume three orientations with respect to the thiazinoquinone/quinone/quinol ring $\left(\tau 2=\sim 60^{\circ}, \sim-60^{\circ}\right.$ and $\sim 180^{\circ}$; Tables 6 and 7 and Table S1). This determined a total number of six conformers (named I-VI; Figure 6). In the case of the thiazinoquinone derivative 2 , due to the presence of the two opposite flips of the thiazinoquinone ring $\left(\tau_{\text {flip }} \sim \pm 60^{\circ}\right)$, we obtained two specular sets of conformers with the same conformational energy (i.e., conformational enantiomers; Figure S10), as previously reported for other thiazinoquinone derivatives $[13,14]$.

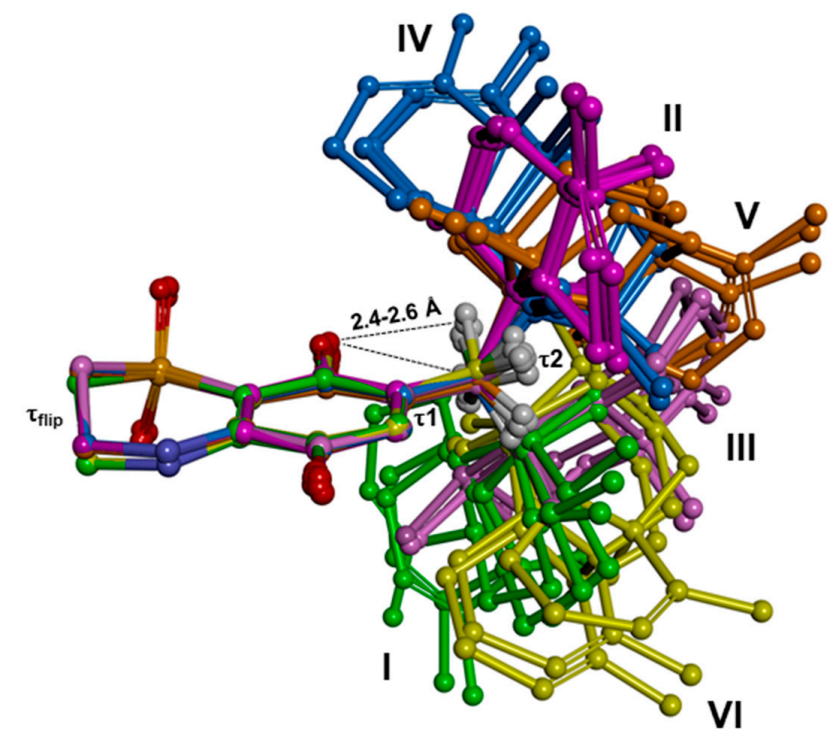

Figure 6. Density functional theory DFT conformers of compounds $\mathbf{1}-\mathbf{3}$ superimposed by the carbon atoms of the quinone/hydroquinone ring. Carbon atoms are colored according to conformer classification ( $\mathrm{I}$ = green, $\mathrm{II}=$ magenta, $\mathrm{III}=$ pink, IV = light blue, $\mathrm{V}=$ orange, and VI = Yellow); heteroatoms are colored by atom type $(\mathrm{H}=$ white, $\mathrm{O}=$ red, $\mathrm{N}=$ blue, $\mathrm{S}=$ orange). Hydrogens are omitted for sake of clarity, with the exception of those of the first methylene group of the $\mathrm{R}^{\prime}$ substituent, whose intramolecular distances from the nearby oxygen atom of the quinone are reported. 
Table 6. $\Delta \mathrm{E}_{\mathrm{GM}}$ values $(\mathrm{kcal} / \mathrm{mol})$ and torsion angle values (degrees) of the DFT conformers of 2 .

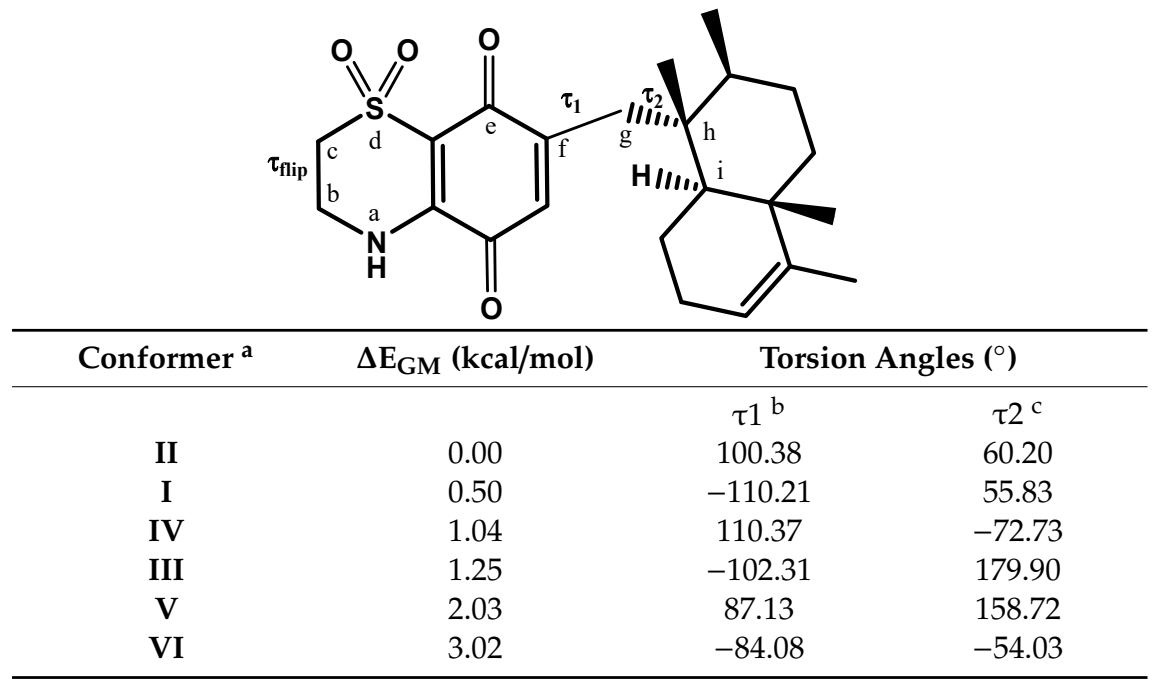

${ }^{a}$ Only the conformational enantiomers with the value of $\tau_{\text {flip }} \sim 60^{\circ}$ are reported. ${ }^{b} \tau 1$ torsion angle is defined by e, $\mathrm{f}$, $\mathrm{g}$, and $\mathrm{h}$ atoms. ${ }^{\mathrm{c}} \tau 2$ torsion angle is calculated considering $\mathrm{f}, \mathrm{g}, \mathrm{h}$, and $\mathrm{i}$ atoms.

Table 7. $\Delta \mathrm{E}_{\mathrm{GM}}$ values $(\mathrm{kcal} / \mathrm{mol})$ and torsion angle values (degrees) of the DFT conformers of $\mathbf{1}$.

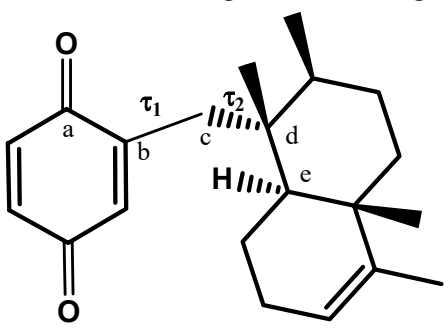

\begin{tabular}{|c|c|c|c|}
\hline \multirow[t]{2}{*}{ Conformer } & \multirow[t]{2}{*}{$\begin{array}{c}\Delta \mathrm{E}_{\mathrm{GM}} \\
\text { (kcal/mol) }\end{array}$} & \multicolumn{2}{|c|}{$\begin{array}{c}\text { Torsion Angles } \\
\left({ }^{\circ}\right)\end{array}$} \\
\hline & & $\tau 1^{\mathrm{a}}$ & $\tau 2^{b}$ \\
\hline I & 0.00 & -91.95 & 64.65 \\
\hline II & 0.01 & 101.16 & 60.62 \\
\hline III & 1.20 & -92.79 & 169.87 \\
\hline IV & 1.25 & 96.73 & -58.29 \\
\hline $\mathbf{V}$ & 2.33 & 84.62 & 173.14 \\
\hline VI & 2.64 & -81.09 & -54.96 \\
\hline
\end{tabular}

${ }^{\mathrm{a}} \tau 1$ torsion angle is defined by $\mathrm{a}, \mathrm{b}, \mathrm{c}$, and d atoms. ${ }^{\mathrm{b}} \tau 2$ torsion angle is calculated considering $\mathrm{b}, \mathrm{c}, \mathrm{d}$, and e atoms.

The fixed position of the methylene group combined with the presence of the rigid sesquiterpene moiety, place in the putative semiquinone radical produced upon one electron reduction/oxidation several hydrogen atoms at a distance $(\leq 3 \AA)$ suitable for an intramolecular radical shift from the oxygen atom to a carbon atom of $\mathrm{R}^{\prime}$ (see below).

Then, starting from the DFT minima, the redox properties of 1-3 were calculated. At this aim, we considered the two electrons/two protons quinone reduction pathway in a protic solvent (Scheme S1) and all the species involved in the pathway $\left(\mathrm{Q}^{\bullet-}, \mathrm{QH}^{\bullet}, \mathrm{QH}^{-}, \mathrm{QH}_{2}\right)$ were generated and DFT optimized using as starting structures the energetically favored DFT minima I and II.

Two possible protonated semiquinone species may be formed, depending on which of the two quinone oxygen atoms is reduced/oxidized at first. The location of the lowest unoccupied molecular orbital (LUMO) in $\mathbf{1}$ and $\mathbf{2}$ and of the highest occupied molecular orbital (HOMO) in $\mathbf{3}$ indicated the oxygen opposite to the alkyl chain as the most probable site to be reduced and the one close to the alkyl chain as the most probable site to be oxidized, respectively (Figure 7). It is worthy to be mentioned 
that, regarding the most probable oxidation pathway of 3 to its quinone form, since the deprotonation step is supposed to be the first event in protic solvents (Scheme S1), we calculated the pKa values of the two hydroxyl groups, too. Results indicated the hydroxyl group nearby the alkyl substituent as the first to lose the proton (Figure S11), further supporting the formation of the hydroquinone radical reported in Figure 7.

A
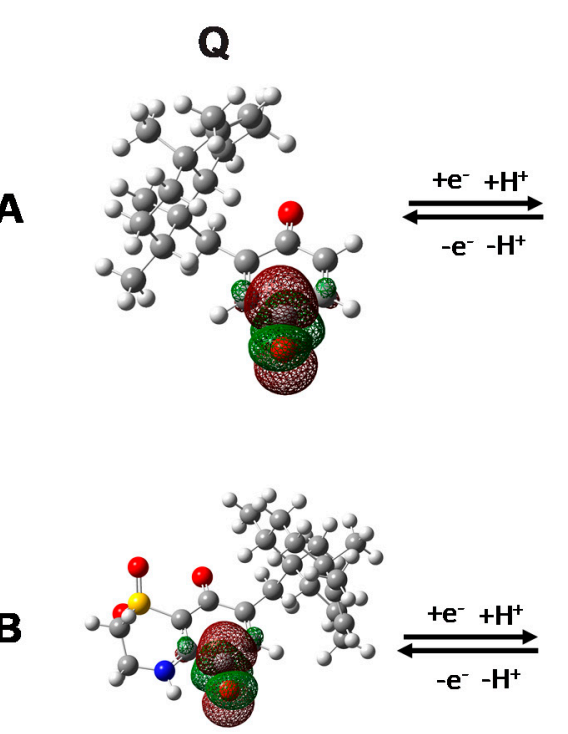
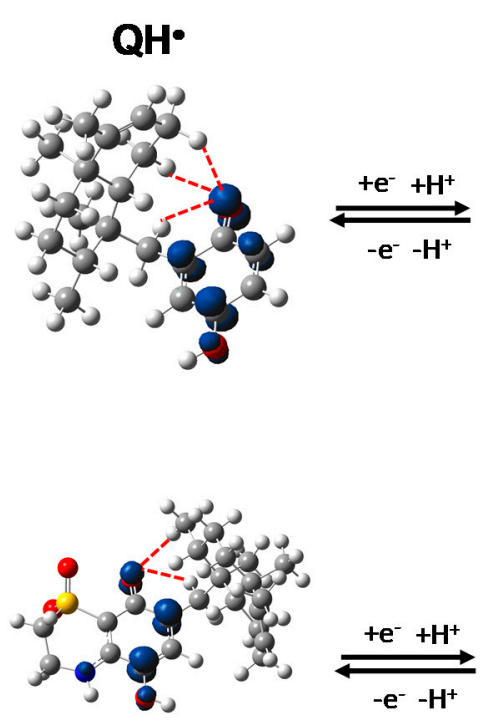
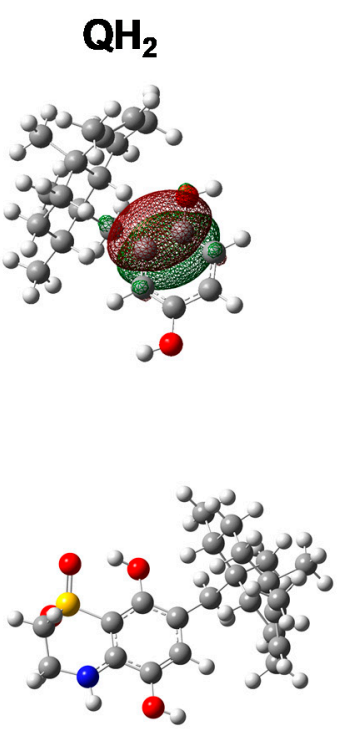

Figure 7. (A): DFT global minimum energy conformer (GM) structure of $\mathbf{1}(\mathrm{Q})$, DFT conformer I of 3 $\left(\mathrm{QH}_{2}\right)$ and their semiquinone radical $\left(\mathrm{QH}^{\bullet}\right)$. (B) DFT GM structure of $\mathbf{2}(\mathrm{Q})$ together with its one- and two-electron reduced species $\mathrm{QH}^{\bullet}$ and $\mathrm{QH}_{2}$. Atoms possibly involved in an intramolecular radical shift are evidenced with red dashed lines. The LUMO of $\mathbf{1}$ and $\mathbf{2}$, and the HOMO of $\mathbf{3}$ are visualized using GaussView with an isosurface value of $0.02 \mathrm{e}^{-} / \mathrm{a}_{\mathrm{u}}{ }^{3}$ The NBO spin density isosurface of the $\mathrm{QH}^{\bullet}$ species is displayed using GaussView with an isosurface value of $0.01 \mathrm{e}^{-} / \mathrm{a} \cdot \mathrm{u}^{3}$. The blue surface (positive spin density) corresponds to an excess of $\alpha$-electron density.

The standard redox potential $\left(\mathrm{E}^{\circ}\right)$ and the standard Gibbs free energy $\left(\Delta \mathrm{G}^{0}\right.$ red, aq $)$ of each electron-transfer reaction (see Scheme S1) alongside with the standard Gibbs free energy required for the protonation of the resulting reduced species $\left(\Delta \mathrm{G}^{0} \mathrm{H}_{+}\right)$of the redox couple $\mathbf{1}, \mathbf{3}$ and $\mathbf{2}$ were calculated (for details see the experimental Section). To further evaluate the propensity of $\mathbf{1}$ and $\mathbf{2}$ to undergo a one-electron reduction, the energy of the lowest unoccupied molecular orbital ( $\left.E_{L U M O}\right)$ was also taken into account. Similarly, we calculated the ionization potential (IP; i.e., $-\mathrm{E}_{\mathrm{HOMO}}$ ) of the radical anion $\mathrm{QH}^{-}$as indicative of the tendency of the deprotonated species of 3 to undergo a one-electron oxidation. Finally, we considered the energy of the single occupied molecular orbital ( $\left.E_{S O M O}\right)$ of the radical species as indicative of the ability to delocalize the unpaired electron. The resulting data are reported in Tables 8 and 9.

Table 8. DFT calculated parameters and standard redox potentials $\left(\mathrm{E}^{\circ} ; \mathrm{Q} / \mathrm{Q}^{\bullet-}\right)$ of compounds 1-3.

\begin{tabular}{|c|c|c|c|c|c|c|c|}
\hline Cmp. & Conf. & $\begin{array}{c}\mathrm{E}_{\text {LUMO }}{ }^{\mathrm{a}} \\
(\mathrm{Q})\end{array}$ & $\begin{array}{c}\text { ESOMO }^{a} \\
\left(Q^{\bullet-}\right)\end{array}$ & $\begin{array}{c}\text { ESOMO }^{a} \\
\left(\mathrm{QH}^{\bullet}\right)\end{array}$ & $\begin{array}{c}\Delta \mathrm{G}^{\circ}{ }_{\text {red, aq }}{ }^{\mathrm{a}} \\
\left(\mathrm{Q}^{\prime} \mathrm{Q}^{\bullet-}\right)\end{array}$ & $\begin{array}{c}E^{\circ b} \\
\left(Q^{\circ} Q^{\bullet-}\right)\end{array}$ & $\begin{array}{c}\Delta \mathrm{G}^{\circ} \mathrm{H}^{\mathrm{a}} \\
\left(\mathrm{Q}^{\bullet-} / \mathrm{QH}^{\bullet}\right)\end{array}$ \\
\hline 1,3 & I & -10.62 & -143.34 & -106.45 & -94.58 & -328.57 & -279.60 \\
\hline 1,3 & II & -10.68 & -143.42 & -106.60 & -95.13 & -304.65 & -279.87 \\
\hline 2 & I & -17.76 & -148.69 & -158.60 & -95.29 & -297.63 & -272.91 \\
\hline 2 & II & -17.83 & -148.72 & -159.93 & -95.66 & -281.68 & -273.03 \\
\hline
\end{tabular}

${ }^{\mathrm{a}} \mathrm{kcal} / \mathrm{mol} .{ }^{\mathrm{b}} \mathrm{mV}$. 
Table 9. DFT calculated parameters and standard redox potentials $\left(\mathrm{E}^{\circ} ; \mathrm{QH}^{\bullet} / \mathrm{QH}^{-}\right)$of compounds 1-3.

\begin{tabular}{|c|c|c|c|c|c|c|}
\hline Cmp. & Conf. & $\begin{array}{l}\Delta \mathrm{G}^{\circ}{ }_{\text {red,aq }}{ }^{\mathrm{a}} \\
\left(\mathrm{QH}^{\bullet} / \mathrm{QH}^{-}\right)\end{array}$ & $\begin{array}{c}E^{\circ b} \\
\left(\mathrm{QH}^{\bullet} / \mathrm{QH}^{-}\right)\end{array}$ & $\begin{array}{c}\Delta \mathrm{G}^{\circ} \mathrm{H+}^{\mathrm{a}} \\
\left(\mathrm{QH}^{-} / \mathrm{QH}_{2}\right)\end{array}$ & $\begin{array}{c}\mathrm{IP}^{\mathrm{a}} \\
\left(\mathrm{QH}^{-}\right)\end{array}$ & $\begin{array}{c}\mathrm{E}_{\mathrm{HOMO}}{ }^{\mathrm{a}} \\
\left(\mathrm{QH}_{2}\right)\end{array}$ \\
\hline 1,3 & I & -91.67 & -454.64 & -295.41 & 61.09 & -158.06 \\
\hline 1,3 & II & -89.95 & -529.31 & -296.77 & 60.83 & -156.34 \\
\hline 2 & I & -95.22 & -300.60 & -290.49 & 130.87 & -158.18 \\
\hline 2 & II & -95.24 & -299.70 & -289.55 & 130.94 & -159.27 \\
\hline
\end{tabular}

${ }^{\mathrm{a}} \mathrm{kcal} / \mathrm{mol} .{ }^{\mathrm{b}} \mathrm{mV}$.

A first consideration can be derived comparing the redox properties of the quinone-based compounds $\mathbf{1}$ and $\mathbf{2}$. With respect to 1, $\mathbf{2}$ showed either a higher tendency to acquire one electron (lower $\mathrm{E}_{\mathrm{LUMO}}$ and $\Delta \mathrm{G}^{0}{ }_{\text {(red, aq) }}$; higher $\mathrm{E}^{\circ}$; Table 8 ) and a higher stability of the $\mathrm{QH}^{\bullet}$ radical (lower $\mathrm{E}_{\mathrm{SOMO}}$; Table 8 ). While the $E_{\mathrm{SOMO}}$ values of the anion radical species showed little difference (ESOMO $\mathrm{Q}^{\bullet-}$; Table 8), on the contrary, the differences became evident after the protonation step (ESOMO $\mathrm{QH}^{\bullet}$ ). These results, on one hand confirm the key role played by the 1,1-dioxo-1,4-thiazine ring on the electron affinity $[11,13,14]$; on the other hand, support the hypothesis that the compound activity is related to the formation of the semiquinone radical species. Indeed, the thiazinoquinone derivative 2 resulted overall more potent than the quinone derivative 1 .

A second consideration is that, as evidenced in Figure 7 and Figure S12, all the calculated semiquinone radicals showed a hydrogen atom of the first methylene group together with, at least, another hydrogen atom of the rigid sesquiterpene ring, at a distance suitable for an intra-molecular hydrogen radical shift to the semi- reduced/oxidized oxygen atom ( $\leq 3 \AA$ ) (Table S2). By consequence, as above mentioned, the presence of the sesquiterpene moiety as alkyl substituent is expected to promote the putative "through space" intramolecular hydrogen radical shift leading to the formation of the toxic radical species. In line with this hypothesis, 2 resulted the most potent thiazinoquinone developed by us against $P$. falciparum D10 and W2 strains as well as against stage $\mathrm{V}$ gametocytes. In addition, 1, although lacking the 1,1-dioxo-1,4-thiazine ring of 2, resulted still active on P. falciparum D10 and W2 strains as well as on schistosomula, contrarily to what previously observed by us for other 1,4-benzoquinone derivatives when compared to the corresponding thiazinoquinone analogues $[13,14]$.

Finally, the hydroquinone 3 showed a higher propensity to be oxidized to the semiquinone radical (i.e., lower $\mathrm{E}^{\circ}$ and $\mathrm{IP}$ of the $\mathrm{QH}^{-}$anion) with respect to the corresponding reduced form of 2 (Table 9). Thus, the absence of the 1,1-dioxo-1,4-thiazine ring favors the one-electron oxidation reaction of 3 .

The hydroquinone 3 resulted more active than the corresponding quinone $\mathbf{1}$ against all considered parasites, while presenting the highest selectivity index with respect to mammalian cells. Both the oxidized and the reduced forms could produce the same putative toxic radical species upon a one-electron transfer reaction. In this view, our results suggest the presence in the parasite cell of a bioactivation reaction partner preferentially binding the hydroquinone (reduced) form (3) rather than the quinone (oxidized) form (1). This putative bioactivation partner seems not to be present in human cells.

To investigate the role played by molecular pharmacokinetics on the observed SARs, we calculated the distribution coefficient values of $\mathbf{1 - 3}$ (clogD, Table S3) (ACD/Percepta 2017). According to Lipinski's rules for drug absorption [50] the thiazinoquinone 2 showed a better cLogD value for cell membrane passive diffusion ( $(\log D \sim 4)$ with respect to 1 and $3(\operatorname{cog} D>5)$. However, in specific developmental stages (i.e., $P f$ late gametocytes, promastigote of L. infantum and L. tropica, amastigote of L. infantum, and adult worms of S. mansoni) 3 resulted more active than 2 (Tables 2, 4 and 5; Figures 4 and 5). According to what previously reported by us [14], this peculiar activity profile could be due to the significant morphological changes in the parasite during the above-mentioned developmental stages [51-53], which are likely to impair compound ability to penetrate into the parasite by passive 
diffusion, while it could still penetrate by exploiting the large number of transport proteins expressed on the parasite membrane.

Taken together, the results of our computational investigation indicate that a toxic semiquinone radical species $[11,13,14]$ which can be produced starting both from quinone- and hydroquinone-based compounds could mediate the anti-parasitic effects of the tested compounds 1-3.

\section{Materials and Methods}

\subsection{General Methods}

Solvents: Carlo Erba (Pomezia, Rome, Italy). Commercial reagents: Sigma-Aldrich (Saint Louis, MO, USA). TLC: Silica Gel 60 F254, plates $5 \times 20,0.25$ mm, Merck (Kenilworth, NJ, USA). Anhydrous solvents: Sigma-Aldrich-Merck. High-resolution ESI-MS analyses were performed on a Thermo LTQ Orbitrap XL mass spectrometer (Thermo-Fisher, San Josè, CA, USA). The spectra were recorded by infusion into the ESI (Thermo-Fisher, San Josè, CA, USA) source dissolving the sample in MeOH. ${ }^{1} \mathrm{H}(500 \mathrm{MHz})$ and ${ }^{13} \mathrm{C}(125 \mathrm{MHz}) \mathrm{NMR}$ spectra were recorded on an Agilent INOVA spectrometer (Agilent Technology, Cernusco sul Naviglio, Italy) equipped with a ${ }^{13} \mathrm{C}$ enhanced HCN Cold Probe; chemical shifts were referenced to the residual solvent signal $\left(\mathrm{CDCl}_{3}: \delta_{\mathrm{H}}=7.26, \delta_{\mathrm{C}}=77.0\right)$. For an accurate measurement of the coupling constants, the one-dimensional ${ }^{1} \mathrm{H}$ NMR spectra were transformed at $64 \mathrm{~K}$ points (digital resolution: $0.09 \mathrm{~Hz}$ ). Homonuclear $\left({ }^{1} \mathrm{H}-{ }^{1} \mathrm{H}\right)$ and heteronuclear $\left({ }^{1} \mathrm{H}-{ }^{13} \mathrm{C}\right)$ connectivities were determined by COSY and HSQC experiments, respectively. Two and three bond ${ }^{1} \mathrm{H}_{-13}{ }^{13} \mathrm{C}$ connectivities were determined by gradient $2 \mathrm{D}$ HMBC experiments optimized for a ${ }^{2,3} \mathrm{~J}$ of $8 \mathrm{~Hz} \cdot{ }^{3} \mathrm{~J}_{\mathrm{H}^{-} \mathrm{H}}$ values were extracted from $1 \mathrm{D}^{1} \mathrm{H}$ NMR. High performance liquid chromatography (HPLC) separations were achieved on a Shimadzu LC-10AT (Shimadzu, Milan, Italy) apparatus equipped with a Knauer K-2301 (LabService Analytica s.r.l., Anzola dell'Emilia, Italy) refractive index.

\subsection{Collection, Extraction and Isolation}

Several fresh specimens of $D$. avara were collected along the coast of Narlidere, Bay of Izmir (Turkey, $38^{\circ} 24^{\prime} 45 \mathrm{~N} 27^{\circ} 8^{\prime} 18 \mathrm{E}$ ), in summer of 2017 and immediately frozen and stored at $-25^{\circ} \mathrm{C}$ until the use. The identification of fresh material was performed by Mr. Arturo Facente while a voucher specimen is deposited at Mugla University, Turkey.

The freshly thawed sponge ( $21.9 \mathrm{~g}$ dry weight after extraction) was homogenized and treated at room temperature with methanol $(3 \times 1 \mathrm{~L})$ and, subsequently, with dichloromethane $(3 \times 1 \mathrm{~L})$. The combined extracts were concentrated in vacuo to give an aqueous suspension that was subsequently extracted with $\mathrm{BuOH}$. The butanol soluble material (5.4 $\mathrm{g}$ of a dark brown oil), obtained after evaporation of the solvent, was chromatographed on a RP-18 silica gel flash column using a gradient elution (water $\rightarrow$ methanol $\rightarrow$ chloroform). The fractions eluted with $\mathrm{H}_{2} \mathrm{O} / \mathrm{MeOH}$ 2:8 $(v / v)$ were chromatographed by HPLC on an RP-18 column (Luna, $3 \mu \mathrm{m} \mathrm{C}-18,150 \times 3.00 \mathrm{~mm}$ ), using $\mathrm{MeOH} / \mathrm{H}_{2} \mathrm{O} 95: 5$ as the eluent (flow $0.5 \mathrm{~mL} / \mathrm{min}$ ). This separation afforded $4.5 \mathrm{mg}$ of pure avarol $\left(3, t_{\mathrm{R}}=5.4 \mathrm{~min}\right)$ and $26.8 \mathrm{mg}$ of avarone $\left(\mathbf{1}, t_{\mathrm{R}}=9.4 \mathrm{~min}\right)$, identified by comparison of its spectral properties with literature values [21-23].

Avarone (1): yellow powder; $[\alpha]_{\mathrm{D}}{ }^{25}=+2.6\left(c 0.0014, \mathrm{CH}_{3} \mathrm{OH}\right) ;{ }^{1} \mathrm{H} \mathrm{NMR}\left(\mathrm{CDCl}_{3}\right)$ spectrum is reported in Supplementary Materials (Figure S6); HRMS (ESI): $\mathrm{m} / z 313.2156[\mathrm{M}+\mathrm{H}]^{+}$(calcd. for $\mathrm{C}_{21} \mathrm{H}_{29} \mathrm{O}_{2}:$ 313.2162) (Figure S7).

Synthesis of thiazoavarone (2). $20.3 \mathrm{mg}$ of avarone (1, $0.065 \mathrm{mmol})$ were dissolved in $12 \mathrm{~mL}$ of a mixture of $\mathrm{CH}_{3} \mathrm{CN} / \mathrm{EtOH} 1: 1(\mathrm{v} / \mathrm{v})$ and kept under stirring at room temperature; then, a solution of hypotaurine $(7 \mathrm{mg}, 0.065 \mathrm{mmol})$ in $2 \mathrm{~mL}$ of water was added dropwise together with a catalytic amount of salcomine added in portions. The mixture was stirred for $48 \mathrm{~h}$ at room temperature before removing the most of ethanol in vacuo and pouring the residue into water. The orange/yellow mixture was extracted with diethyl ether $(60 \mathrm{~mL} \times$ three times) and the organic phase was washed with brine, dried over sodium sulfate, filtered, and solvent was removed by rotary evaporator. The resulting mixture 
was chromatographed by HPLC on an RP-18 column (Luna, $3 \mu \mathrm{m} \mathrm{C-18,} 150 \times 3.00 \mathrm{~mm}$ ) eluting with $\mathrm{MeOH} / \mathrm{H}_{2} \mathrm{O} 75: 25\left(t_{\mathrm{R}}=31.6 \mathrm{~min}\right)$ and afforded the pure compound $2(11 \mathrm{mg}, 46 \%)$.

Thiazoavarone (2): orange powder; $[\alpha]_{\mathrm{D}}{ }^{25}=+19.2\left(c 0.0035, \mathrm{CDCl}_{3}\right) ;{ }^{1} \mathrm{H}$ and ${ }^{13} \mathrm{C} \mathrm{NMR}$ data are reported in Table 1. 1D and 2D NMR data, Figures S2-S5; HRMS (ESI): m/z 440.1865 [M + Na] ${ }^{+}$(calcd. for $\mathrm{C}_{23} \mathrm{H}_{31} \mathrm{NO}_{4} \mathrm{SNa}$ : 440.1866) (Figure $\mathrm{S} 1$ ).

Avarol (3): yellow powder; $[\alpha]_{\mathrm{D}}{ }^{25}=+12.4\left(c 0.0018, \mathrm{CH}_{3} \mathrm{OH}\right) ;{ }^{1} \mathrm{H} \mathrm{NMR}\left(\mathrm{CDCl}_{3}\right)$ spectrum is reported in Supplementary Materials (Figure S8); HRMS (ESI): $m / z 315.2337[\mathrm{M}+\mathrm{H}]^{+}$(calcd. for $\mathrm{C}_{21} \mathrm{H}_{31} \mathrm{O}_{2}$ : 315.2319) (Figure S9).

\subsection{P. falciparum Cultures and Drug Susceptibility Assay}

P. falciparum cultures were carried out according to Trager and Jensen with slight modifications [13]. The CQ-sensitive strain D10 and the CQ-resistant strain W2 were maintained at 5\% hematocrit (human type A-positive red blood cells) in RPMI 1640 (EuroClone, Celbio) medium with the addition of 1\% AlbuMax (Invitrogen, Milan, Italy), $0.01 \%$ hypoxanthine, $20 \mathrm{mM}$ Hepes, and $2 \mathrm{mM}$ glutamine at $37^{\circ} \mathrm{C}$ in a standard gas mixture $\left(1 \% \mathrm{O}_{2}, 5 \% \mathrm{CO}_{2}\right.$, and $\left.94 \% \mathrm{~N}_{2}\right)$. All compounds were dissolved in DMSO and then diluted with medium to achieve the required concentrations (final DMSO concentration $<1 \%$, non-toxic to the parasite). Drugs were placed in 96-well flat-bottomed microplates and serial dilutions made. Asynchronous cultures with parasitaemia of $1 \%-1.5 \%$ and $1 \%$ final hematocrit were aliquoted into the plates and incubated for $72 \mathrm{~h}$ at $37^{\circ} \mathrm{C}$. Parasite growth was determined spectrophotometrically (OD650) by measuring the activity of the parasite lactate dehydrogenase (pLDH), according to a modified version of the method of Makler in control and drug-treated cultures [13]. The antiplasmodial activity is expressed as $50 \%$ inhibitory concentrations $\left(\mathrm{IC}_{50}\right)$; each $\mathrm{IC}_{50}$ value is the mean \pm standard deviation of at least three separate experiments performed in duplicate.

\subsection{Gametocytes Cultivation and Susceptibility Assay}

The transgenic P. falciparum 3D7 strain 3D7elo1-pfs16-CBG99 expressing the Pyrophorus plagiophthalamus CBG99 luciferase under a gametocyte specific promoter was used in all the experiments. Parasites were cultured and gametocytes obtained as previously described [54]. Late-stage gametocytes were exposed to compounds at day 11 after $N$-acetylglucosamine (NAG) addition. Gametocytes stages were counted in Giemsa stained smears and the percentage of stage $\mathrm{V}$ gametocytes was higher than $80 \%$. Compounds were prepared by serial dilution, in 96-well plate, in complete medium. Plates were incubated for $72 \mathrm{~h}$ at $37^{\circ} \mathrm{C}$ under $1 \% \mathrm{O}_{2}, 5 \% \mathrm{CO}_{2}, 94 \% \mathrm{~N}_{2}$ atmosphere. Luciferase activity was taken as measure of gametocytes viability, as previously described [55]. Briefly, drug-treated gametocyte samples at $2 \%$ haematocrit were transferred to 96 -well black microplates and D-luciferin $(1 \mathrm{mM}$ in citrate buffer $0.1 \mathrm{M}, \mathrm{pH} 5.5$ ) was added at a 1:1 volume ratio. Luminescence measurements were performed after $10 \mathrm{~min}$ with $500 \mathrm{~ms}$ integration time using a Sinergy 4 (Biotek) microplate reader. The $\mathrm{IC}_{50}$ was extrapolated from the non-linear regression analysis of the concentration-response curve.

\subsection{In Vitro Promastigote Susceptibility Assays}

Promastigote stage of L. infantum strain MHOM/TN/80/IPT1 and L. tropica (MHOM/IT/2012/ISS3130) were cultured in Schneider's Drosophila medium (Lonza) supplemented with $10 \%$ heat-inactivated fetal calf serum (HyClone) at $24{ }^{\circ} \mathrm{C}$.

The complete medium used for antileishmanial activity assay was RPMI (EuroClone) supplemented with $10 \%$ heat-inactivated fetal calf serum (EuroClone), $20 \mathrm{mM}$ Hepes, and $2 \mathrm{mM}$ L-glutamine. To estimate the $50 \%$ inhibitory concentration ( $\mathrm{IC}_{50}$ ), the MTT (3-[4.5-dimethylthiazol-2-yl]-2.5-diphenyltetrazolium bromide) method was used. Compounds were dissolved in DMSO and then diluted with medium to achieve the required concentrations. Drugs were placed in 96-well round-bottom microplates and seven serial dilutions made. Amphotericin $\mathrm{B}$ was used as the reference anti-leishmanial drug. Parasites were diluted in complete medium to $5 \times 10^{6}$ parasites $/ \mathrm{mL}$ and $100 \mu \mathrm{L}$ of the suspension was seeded into the plates, incubated at $24{ }^{\circ} \mathrm{C}$ for 
$72 \mathrm{~h}$ and then $20 \mu \mathrm{L}$ of MTT solution $(5 \mathrm{mg} / \mathrm{mL})$ was added into each well for $3 \mathrm{~h}$. The plates were then centrifuged, the supernatants discarded and the resulting pellets dissolved in $100 \mu \mathrm{L}$ of lysing buffer consisting of $20 \%$ (w/v) of a solution of SDS (Sigma), $40 \%$ of $N, N$-dimethylformamide (Merck) in $\mathrm{H}_{2} \mathrm{O}$. The absorbance was measured spectrophotometrically at a test wavelength of $550 \mathrm{~nm}$ and a reference wavelength of $650 \mathrm{~nm}$. The results are expressed as $\mathrm{IC}_{50}$ which is the dose of compound necessary to inhibit parasite growth by $50 \%$; each $\mathrm{IC}_{50}$ value is the mean \pm standard deviation of separate experiments performed in duplicate.

\subsection{In Vitro Intracellular Amastigote Susceptibility Assays}

THP-1 cells (human acute monocytic leukemia cell line) were maintained in RPMI supplemented with $10 \%$ FBS (EuroClone), $50 \mu \mathrm{M}$ 2-mercaptoethanol, $20 \mathrm{mM}$ Hepes, $2 \mathrm{mM}$ glutamine, at $37^{\circ} \mathrm{C}$ in $5 \%$ $\mathrm{CO}_{2}$. For Leishmania infections, THP- 1 cells were plated at $5 \times 10^{5}$ cells $/ \mathrm{mL}$ in 16 -chamber Lab-Tek culture slides (Nunc) and treated with $0.1 \mu \mathrm{M}$ phorbol myristate acetate (PMA, Sigma) for $48 \mathrm{~h}$ to achieve differentiation into macrophages. Cells were washed and infected with metacyclic $L$. infantum promastigotes at a macrophage/promastigote ratio of $1 / 10$ for $24 \mathrm{~h}$. Cell monolayers were then washed and incubated in the presence of test compounds for $72 \mathrm{~h}$. Slides were fixed with methanol and stained with Giemsa. The percentage of infected macrophages in treated and non-treated cells was determined by light microscopy.

\subsection{Cytotoxicity Assay}

The long-term human microvascular endothelial cell line (HMEC-1) was maintained in MCDB 131 medium (Invitrogen, Milan, Italy) supplemented with 10\% fetal calf serum (HyClone, Celbio, Milan, Italy), $10 \mathrm{ng} / \mathrm{mL}$ of epidermal growth factor, $1 \mu \mathrm{g} / \mathrm{ml}$ of hydrocortisone, $2 \mathrm{mM}$ glutamine and $20 \mathrm{mM}$ Hepes buffer (EuroClone). For the cytotoxicity assays, HMEC-1 were plated at $10^{5}$ cells $/ \mathrm{mL}$ in 96-well flat bottom microplates. THP-1 cells were plated at $5 \times 10^{5}$ cells $/ \mathrm{mL}$ in 96 -well flat bottom microplates and treated with $0.1 \mu \mathrm{M}$ PMA for $48 \mathrm{~h}$ to achieve differentiation into macrophages. Cells were then treated with serial dilutions of test compounds and cell proliferation evaluated using the MTT assay described for promastigotes. The results are expressed as $\mathrm{IC}_{50}$, which is the dose of compound necessary to inhibit cell growth by $50 \%$.

\subsection{In vitro Effects of Compounds on S. mansoni Parasites and Eggs}

Schistosomula were prepared by mechanical transformation of cercariae, as previously described [56]. The ATP-based viability assay with CellTiterGlo (Promega, Italy) on the larval stage of schistosomes was carried out in 96-well, black, tissue culture plates by adaptation of a protocol previously set up in our laboratory [56]. DMSO (vehicle) and gambogic acid $(10 \mu \mathrm{M})$ were used as the negative and positive controls in each plate and the percentage of viability for each compound was calculated as the ATP reduction against vehicle $(0 \%)$ and gambogic acid $(100 \%)$.

All Animal work was approved by the National Research Council, Institute of Cell Biology and Neurobiology animal welfare committee (OPBA) and by the competent authorities of the Italian Ministry of Health, DGSAF, Rome (authorization no. 25/2014-PR and no. 336/2018-PR). All experiments were conducted in respect to the $3 \mathrm{R}$ rules according to the ethical and safety rules and guidelines for the use of animals in biomedical research provided by the relevant Italian law and European Union Directive (Italian Legislative Decree 26/2014 and 2010/63/EU) and the International Guiding Principles for Biomedical Research involving animals (Council for the International Organizations of Medical Sciences, Geneva, Switzerland).

A Puerto Rican strain of $S$. mansoni was maintained by passage through albino Biomphalaria glabrata, as the intermediate host, and ICR (CD-1) outbred female mice as previously described [56]. Female 4 to 7-week-old mice (Envigo, Udine, Italy) were infected with 200-400 double sex S. mansoni cercariae by the tail immersion technique. Adult pairs were harvested from mice 7-8 weeks after infection by reversed perfusion of the hepatic portal system and mesenteric veins. For the viability 
assays, 5 couples were incubated with the compounds in $3 \mathrm{~mL}$ DMEM complete tissue culture medium containing $10 \%$ FBS for up to 7 days and phenotypic score was assigned as previously described [57]. For egg-treatment, 5 worm pairs were incubated for $48 \mathrm{~h}$ in $3 \mathrm{~mL}$ complete tissue culture medium; next the parasites were removed and vehicle (DMSO) or compounds 1-3 were added to each plate containing the eggs previously laid in vitro and observed for $72 \mathrm{~h}$ as previously reported [14]. Briefly, images were recorded with a BX41 Olympus microscope and a bright field objective $10 \times$ served by a SPOT RT 220-3 Diagnostic Instrument Inc camera. Egg maturation/morphological score was assigned based on the Vogel and Prata' staging system of egg maturation [47].

\subsection{Molecular Modelling}

Molecular modelling calculations were performed on E4 Server Twin $2 \times$ Dual Xeon-5520, equipped with two nodes. Each node: $2 \times$ Intel ${ }^{\circledR}$ Xeon ${ }^{\circledR}$ QuadCore E5520-2.26Ghz, 36 GB RAM. The molecular modelling graphics were carried out on a personal computer equipped with Intel(R) Core(TM) i7-4790 processor and SGI Octane 2 workstations.

Conformational property analysis. The apparent $\mathrm{pKa}$ and $\log \mathrm{D}$ values ( $\mathrm{pH} 7.4$ and 7.2) of compounds were calculated by using the ACD/Percepta software (ACD/Percepta, Advanced Chemistry Development, Inc., Toronto, ON, Canada, 2017, http://www.acdlabs.com).

The compounds were considered neutral in all calculations performed as a consequence of the estimation of percentage of neutral/ionized forms computed at $\mathrm{pH} 7.4$ (blood $\mathrm{pH}$ value) and $\mathrm{pH} 7.2$ (cytoplasm $\mathrm{pH}$ value) using the Henderson-Hasselbalch equation. The compounds were built using the Small Molecule tool of Discovery Studio 2017 (Dassault Systèmes BIOVIA, San Diego). Then, the built compounds were subjected to molecular mechanic $(\mathrm{MM})$ energy minimization $(\varepsilon=80 \times r)$ until the maximum RMS derivative was less than $0.001 \mathrm{kcal} / \AA$, using Conjugate Gradient [58] as minimization algorithm. Atomic potentials and charges were assigned using the CFF forcefield [48]. The conformers obtained for each compound were used as starting structure for the subsequent systematic conformational analysis (Search Small Molecule Conformations; Discovery Studio 2017). The conformational space of the compounds was sampled by systematically varying the rotatable bonds $\mathrm{sp}^{3}-\mathrm{sp}^{3}$ and $\mathrm{sp}^{3}-\mathrm{sp}^{2}$ with an increment of $60^{\circ}$. The RMSD cutoff for structure selection was set to $0.01 \AA$. Finally, to ensure a wide variance of the input structures to be successively fully minimized, an energy threshold value of $10^{6} \mathrm{kcal} / \mathrm{mol}$ was used as selection criteria. The generated structures were then subjected to MM energy minimization (CFF forcefield; $\varepsilon=80 \times r$ ) until the maximum RMS derivative was less than $0.001 \mathrm{kcal} / \AA$, using Conjugate Gradient as minimization algorithm. Finally, the resulting conformers were ranked by their potential energy values (i.e., $\Delta \mathrm{E}$ from the global energy minimum $(\mathrm{GM}))$.

All MM conformers within $5 \mathrm{kcal} / \mathrm{mol}$ from GM has been then subjected to DFT calculations. The calculations were carried out using the Gaussian 09 package [59]. All structures were fully optimized at the B3LYP/6-31+G $(\mathrm{d}, \mathrm{p})$ level using the conductor-like polarizable continuum model (C-PCM) [49,60,61]. In order to characterize every structure as minimum and to calculate the Gibbs free energy a vibrational analysis was carried out at the same level of theory using the keyword: freq. The RMS force criterion was set to $3 \times 10^{-4}$ a.u. Partial charges, molecular orbitals and spin density have been calculated using the natural bond orbital (NBO) method [62]. The resulting conformers were ranked by their potential energy values (i.e., $\Delta \mathrm{E}$ from the global energy minimum (GM)) and classified by their dihedral angle values).

Calculation of redox properties. An appropriate way for calculating the redox potential is by using a thermodynamic cycle. Accordingly, the redox potentials for the compounds was calculated by using the Born-Haber cycle (Scheme 2), which links the Gibbs free energy change of the one-electron transfer reaction in the gas phase with that of the same reaction in aqueous solution $[63,64]$. 


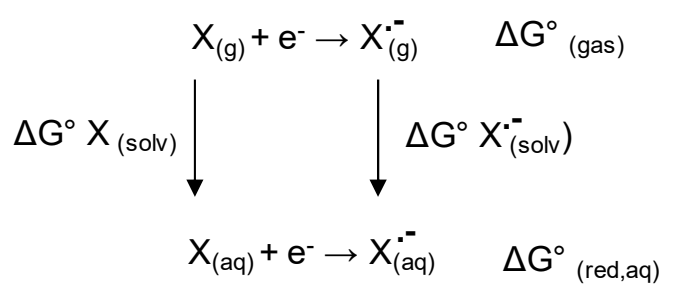

Scheme 2. Born-Haber cycle for a generic one-electron transfer reaction in vacuo and in aqueous solution.

Accordingly, the Born-Haber thermodynamic cycle allows to include the desolvation/solvation effects by calculating the Gibbs free energy values of the reaction in gas phase and in solution. According to this approach, the standard Gibbs free energy of the electron transfer $\left(\Delta G_{r e d, a q}^{0}\right)$, was calculated taking into account the free energy change in the gas phase $\left(\Delta G_{\text {gas }}^{0}\right)$ and the solvation free energies of the oxidized $\left(\Delta G_{\text {solv }}^{0}(X)\right)$ and reduced species $\left(\Delta G_{\text {solv }}^{0}\left(X^{\bullet-}\right)\right)$ as reported in the following equation:

$$
\Delta G_{r e d, a q}^{0}=\Delta G_{\text {gas }}^{0}+\left(\Delta G_{\text {solv }}^{0}\left(X^{\bullet-}\right)-\Delta G_{\text {solv }}^{0}(X)\right)
$$

Accordingly, we, firstly, calculated the Gibbs free energy in gas phase by using the following equation:

$$
\Delta G_{g a s}^{0}=G_{g a s}^{0}\left(X^{\bullet-}\right)-G_{g a s}^{0}(X)
$$

Then, the Gibbs free energy of solvation of both the species $X$ and $X^{\bullet-}$ were calculated according to the following equations:

$$
\begin{gathered}
\Delta G_{\text {solv }}^{0}(X)=G_{a q}^{0}(X)-G_{\text {gas }}^{0}(X) \\
\Delta G_{\text {solv }}^{0}\left(X^{-}\right)=G_{a q}^{0}\left(X^{\bullet-}\right)-G_{\text {gas }}^{0}\left(X^{\bullet-}\right)
\end{gathered}
$$

The values obtained were used to calculate the standard Gibbs free energy of the overall reaction $\left(\Delta G_{r e d, a q}^{0} ; \mathrm{kcal} \cdot \mathrm{mol}^{-1}\right)$ according to Equation (1). The $\mathrm{X}$ and $\mathrm{X}^{\bullet-}$ species correspond in our case to $\mathrm{Q}$ and $\mathrm{Q}^{\bullet-}$, respectively in the first electron transfer, and to $\mathrm{QH}^{\bullet}$ and $\mathrm{QH}^{-}$in the second electron transfer (see Scheme S1).

Finally, the $\Delta G_{r e d, a q}^{0}$, were used to calculate the standard reduction potential by the Nernst equation:

$$
E^{0}=-\frac{\Delta G_{r e d, a q}^{0}}{n F}
$$

where $n$ is the number of electrons involved in the process (i.e., 1) and $F$ the Faraday constant $\left(23.06 \mathrm{kcal} \mathrm{mol}^{-1} \mathrm{~V}^{-1}\right)$.

The reduction potential given by the Equation (5) is an absolute value of the parameter and has to be referred to the standard hydrogen electrode (SHE; redox potential of $4.43 \mathrm{~V}$ ), to obtain the standard redox potential. Accordingly, the value of $4.43 \mathrm{~V}$ was subtracted from the values obtained by Equation (5).

On these bases, in order to calculate the redox potential, starting from the structure of the DFT $\mathrm{Q}$ GM conformers (i.e., the starting quinone species), the redox states $\mathrm{Q}^{\bullet-}, \mathrm{QH}^{\bullet}, \mathrm{QH}^{-}, \mathrm{QH}_{2}$ were generated. Following the reduction pathway of quinones showed in Scheme S1, each species was generated starting from the DFT optimized species of the previous step and submitted to full DFT optimization both in aqueous solution (using the C-PCM method) and in vacuo using the same parameters above described.

The standard Gibbs free energy for the protonation of the reduced species were calculated by determining $\Delta \mathrm{G}^{\circ}$ of the reaction $\mathrm{Y}+\mathrm{H}^{+} \rightarrow \mathrm{YH}$ that is $\Delta \mathrm{G}^{\circ}=\mathrm{G}^{\circ}(\mathrm{YH})-\mathrm{G}^{\circ}(\mathrm{Y})$, where $\mathrm{Y}$ is $\mathrm{Q}^{\bullet-}$ or $\mathrm{QH}^{-}$ DFT conformer. The energy of the frontier molecular orbitals (HOMO, LUMO, and SOMO) were considered for the species $\mathrm{Q}, \mathrm{Q}^{\bullet-}, \mathrm{QH}^{\bullet}$ and $\mathrm{QH}^{-}$fully optimized by DFT calculations performed in the 
aqueous solution (using the C-PCM method). According to the Koopmans' theorem [65], the ionization potential (IP) is given by the negative of the value of the energy of the HOMO.

\section{Conclusions}

We investigated the antiparasitic potential of the marine sesquiterpene avarone (1), its reduced form avarol (3), and thiazoavarone (2), a novel semisynthetic thiazinoquinone analogue obtained through a condensation reaction of 1 with hypotaurine, which resulted completely regioselective. Both the natural metabolites $\mathbf{1}$ and $\mathbf{3}$, as well as the semisynthetic derivative $\mathbf{2}$ resulted active against D10 and W2 strains and late stage gametocytes of $P$. falciparum, against larval and adult developmental stages, and eggs of the platyhelminth S. mansoni, and also against promastigote and amastigote forms of $L$. infantum and L. tropica. The observed differences in the magnitude of the effects of the three molecules allowed us to draw some interesting conclusions, strongly supported by the results of the DFT analysis. In particular, the thiazinoquinone $\mathbf{2}$ resulted as significantly more potent than the quinone derivative $\mathbf{1}$ against D10 and W2 strains of P. falciparum as well as on the larval stage of S. mansoni. On the other hand, compound 1, although lacking the 1,1-dioxo-1,4-thiazine ring, resulted still active on P. falciparum and on Schistosoma larval stage, contrarily to what previously observed for other 1,4-benzoquinone derivatives when compared to the corresponding thiazinoquinone analogues $[13,14]$. The calculated redox properties of $\mathbf{1}$ and $\mathbf{2}$ evidenced for $\mathbf{2}$ either a higher tendency to acquire one electron and a higher stability of the $\mathrm{QH}^{\bullet}$ radical. Noteworthy, thiazoavarone 2 resulted the most potent antimalarial thiazinoquinone developed by us.

The hydroquinone 3 resulted more active than the corresponding quinone $\mathbf{1}$ against all considered parasites, with the highest selectivity index with respect to mammalian cells. This led to hypothesize the presence in the studied parasites of a bioactivation reaction partner preferentially binding the reduced form (3) rather than the oxidized form (1). This putative bioactivation partner seems not to be present in human cells. Finally, comparison of the standard redox potential $\left(\mathrm{E}^{\circ}\right)$ and of the ionization potential (IP) of the $\mathrm{QH}^{-}$anion of 3 with those of the corresponding reduced form of 2 , indicated a higher propensity of 3 to be oxidized to the semiquinone radical and, thus, that the absence of the 1,1-dioxo-1,4-thiazine ring favours the one-electron oxidation reaction of 3.

These results confirm the key role played by the 1,1-dioxo-1,4-thiazine ring on the electron affinity $[11,13,14]$ and, mainly, corroborate the hypothesis that the compound activity is related to the formation of a toxic semiquinone radical species, which can be produced, upon a one-electron transfer reaction, starting both from quinone- and hydroquinone-based compounds. In the case of the antiplasmodial activity (on the erythrocytic stage of the parasite), our previous results indicated that the bioactivation partner can be represented by free heme (generated during hemoglobin digestion) [11,13]. On the contrary, in the case of S. mansoni as well as Leishmania parasites, at this stage, we do not know the bioactivation partner of the compounds. However, reactive oxygen species (ROS) generation was found to be involved in the pro-apoptotic mechanism of some natural marine derived thiazinoquinones against Jurkat cells [66]. Thus, it cannot be ruled out that the putative semiquinone radical species reacts with oxygen molecules in cells, generating ROS and future studies will be devoted to clarifying this issue. Moreover, the observed difference between the activity trend of 1-3 against the different parasites and their developmental stage may be related to morphological and/or metabolic differences in the targeted organism/stage. Thus, the selective toxicity against the different parasites and their developmental stages can be addressed, taking advantage of the possible bioactivation reaction partners to form the putative toxic radical (i.e., one-electron reduction or oxidation reaction).

Supplementary Materials: The following are available online at http://www.mdpi.com/1660-3397/18/2/112/s1, Figure S1. HRESIMS spectrum of thiazoavarone (2), Figure S2. 1H NMR spectrum of thiazoavarone (2) in CDCl3, Figure S3. 1H-1H COSY spectrum of thiazoavarone (2) in CDCl3, Figure S4. HSQC spectrum of thiazoavarone (2) in CDCl3, Figure S5. HMBC spectrum of thiazoavarone (2) in CDCl3, Figure S6. HRESIMS spectrum of avarone (1), Figure S7. 1H-NMR spectrum of avarone (1) in CDCl3, Figure S8. HRESIMS spectrum of avarol (3), Figure S9. 1H-NMR spectrum of avarol (3) in CDCl3, Figure S10. Conformational enantiomers of thiazoavarone (2), Figure S11. Calculated pka values of avarol (3) (ACD/Percepta software), Figure S12. DFT conformer of 1-3, 
and their radical species, Table S1. $\triangle$ EGM values and torsion angle values of the DFT conformers of avarol (3), Table S2. Hydrogen atoms suitable for an intramolecular radical shift, Table S3. cLogD values of 1-3, Scheme S1. Reduction pathway of quinones in a protic solvent.

Author Contributions: Conceptualization, C.I., C.F. and M.M.; data curation, C.I., R.G., M.P., M.C., A.G., F.S., G.R., P.L., A.A., C.F. and M.M.; formal analysis, C.I., R.G., M.P., M.C., A.G., F.S., G.R., S.P. and S.A.; funding acquisition, G.R., C.F. and M.M.; investigation, C.I., R.G., M.P., M.C., A.G. and F.S.; methodology, C.I., R.G., M.P., M.C., G.R., S.P., N.B., C.F. and M.M.; resources, S.A.; writing-original draft, C.I., R.G., M.P., M.C., G.R., N.B., C.F. and M.M.; writing-review and editing, C.I., R.G., M.P., M.C., A.G., F.S., G.R., P.L., A.A., S.P., S.A., N.B., C.F. and M.M. All authors have read and agree to the published version of the manuscript.

Funding: This research was supported by Ministero dell'Istruzione, dell'Università e della Ricerca (MIUR), PRIN Projects 2010C2LKKJ_006; 20154JRJPP_004, by a grant from Regione Campania-POR Campania FESR 2014/2020 “Combattere la resistenza tumorale: piattaforma integrata multidisciplinare per un approccio tecnologico innovativo alle oncoterapie-Campania Oncoterapie" (Project N. B61G18000470007) and by the CNR (National Research Council)-CNCCS (Collezione Nazionale di Composti Chimici e Centro di screening) “Rare, Neglected and Poverty Related Diseases - Schistodiscovery Project" (DSB.AD011.001.003).

Acknowledgments: We wish to thank Asli Kacar and Burcu Omuzbuken for sample collection, and Arturo Facente for identifying the organism.

Conflicts of Interest: The authors declare no conflict of interest.

\section{References}

1. World Health Organization. World Malaria Report 2019. Available online: https://www.who.int/publicationsdetail/world-malaria-report-2019 (accessed on 4 December 2019).

2. World Health Organization. Neglected Tropical Diseases. Program. 2019. Available online: https: //www.who.int/neglected_diseases/en/ (accessed on 27 December 2019).

3. Steinmann, P.; Utzinger, J.; Du, Z.W.; Zhou, X.N. Multiparasitism: A neglected reality on global, regional and local scale. Adv. Parasitol. 2010, 73, 21-50.

4. Newman, D.J.; Cragg, G.M. Natural products as sources of new drugs from 1981 to 2014. J. Nat. Prod. 2016, 79, 629-661. [CrossRef]

5. Mayer, A.M.S.; Rodríguez, A.D.; Taglialatela-Scafati, O.; Fusetani, N. Marine Pharmacology in 2012-2013: Marine Compounds with Antibacterial, Antidiabetic, Antifungal, Anti-Inflammatory, Antiprotozoal, Antituberculosis, and Antiviral Activities; Affecting the Immune and Nervous Systems, and Other Miscellaneous. Mar. Drugs 2017, 15, E273. [CrossRef] [PubMed]

6. Loo, C.S.N.; Lam, N.S.K.; Yu, D.; Su, X.-Z.; Lu, F. Artemisinin and its derivatives in treating protozoan infections beyond malaria. Pharmacol. Res. 2017, 117, 192-217. [CrossRef] [PubMed]

7. Chua, M.J.; Arnold, M.S.J.; Xu, W.; Lancelot, J.; Lamotte, S.; Späth, G.F.; Prina, E.; Pierce, R.J.; Fairlie, D.P.; Skinner-Adams, T.S.; et al. Effect of clinically approved HDAC inhibitors on Plasmodium, Leishmania and Schistosoma parasite growth. Int. J. Parasitol. Drugs Drug Resist. 2017, 7, 42-50. [CrossRef]

8. Chen, M.M.; Shi, L.; Sullivan, D.J., Jr. Haemoproteus and Schistosoma synthesize heme polymers similar to Plasmodium hemozoin and beta-hematin. Mol. Biochem. Parasitol. 2001, 113, 1-8. [CrossRef]

9. Egan, T.J. Recent advances in understanding the mechanism of hemozoin (malaria pigment) formation. J. Inorg. Biochem. 2008, 102, 1288-1299. [CrossRef] [PubMed]

10. Aiello, A.; Fattorusso, E.; Luciano, P.; Mangoni, A.; Menna, M. Isolation and structure determination of aplidinones A-C from the Mediterranean ascidian Aplidium conicum: A successful regiochemistry assignment by quantum mechanical ${ }^{13} \mathrm{C}$ NMR chemical shift calculations. Eur. J. Org. Chem. 2005, 5024-5030. [CrossRef]

11. Imperatore, C.; Persico, M.; Aiello, A.; Luciano, P.; Guiso, M.; Sanasi, M.F.; Taramelli, D.; Parapini, S.; Cebrián-Torrejón, G.; Doménech-Carbó, A.; et al. Marine inspired antiplasmodial thiazinoquinones: Synthesis, computational studies and electrochemical assays. RSC Adv. 2015, 5, 70689-70702. [CrossRef]

12. Imperatore, C.; Cimino, P.; Cebrián-Torrejón, G.; Persico, M.; Aiello, A.; Senese, M.; Fattorusso, C.; Menna, M.; Doménech-Carbó, A. Insight into the mechanism of action of marine cytotoxic thiazinoquinones. Mar. Drugs 2017, 15, 335. [CrossRef]

13. Imperatore, C.; Persico, M.; Senese, M.; Aiello, A.; Casertano, M.; Luciano, P.; Basilico, N.; Parapini, S.; Paladino, A.; Fattorusso, C.; et al. Exploring the antimalarial potential of the methoxy-thiazinoquinone scaffold: Identification of a new lead candidate. Bioorg. Chem. 2019, 85, 240-252. [CrossRef] 
14. Gimmelli, R.; Persico, M.; Imperatore, C.; Saccoccia, F.; Guidi, A.; Casertano, M.; Luciano, P.; Pietrantoni, A.; Bertuccini, L.; Paladino, A.; et al. Thiazinoquinones as New Promising Multistage Schistosomicidal Compounds Impacting Schistosoma mansoni and Egg Viability. ACS Infect. Dis. 2020, 6, 124-137. [CrossRef] [PubMed]

15. Imperatore, C.; Della Sala, G.; Casertano, M.; Luciano, P.; Aiello, A.; Laurenzana, I.; Piccoli, P.; Menna, M. In vitro Antiproliferative Evaluation of Synthetic Meroterpenes Inspired by Marine Natural Products. Mar. Drugs 2019, 17, 684. [CrossRef] [PubMed]

16. Menna, M.; Aiello, A.; D’Aniello, F.; Fattorusso, E.; Imperatore, C.; Luciano, P.; Vitalone, R. Further investigation of the mediterranean sponge Axinella polypoides: Isolation of a new cyclonucleoside and a new betaine. Mar. Drugs 2012, 10, 2509-2518. [CrossRef] [PubMed]

17. Imperatore, C.; Luciano, P.; Aiello, A.; Vitalone, R.; Irace, C.; Santamaria, R.; Li, J.; Guo, Y.-W.; Menna, M. Structure and Configuration of Phosphoeleganin, a Protein Tyrosine Phosphatase 1B Inhibitor from the Mediterranean Ascidian Sidnyum elegans. J. Nat. Prod. 2016, 79, 1144-1148. [CrossRef] [PubMed]

18. Imperatore, C.; D’Aniello, F.; Aiello, A.; Fiorucci, S.; D’Amore, C.; Sepe, V.; Menna, M. Phallusiasterols A and B: Two new sulfated sterols from the Mediterranean tunicate Phallusia fumigata and their effects as modulators of the PXR receptor. Mar. Drugs 2014, 12, 2066-2078. [CrossRef] [PubMed]

19. Luciano, P.; Imperatore, C.; Senese, M.; Aiello, A.; Casertano, M.; Guo, Y.; Menna, M. Assignment of the Absolute Configuration of Phosphoeleganin via Synthesis of Model Compounds. J. Nat. Prod. 2017, 80, 2118-2123. [CrossRef]

20. Casertano, M.; Imperatore, C.; Luciano, P.; Aiello, A.; Putra, M.Y.; Gimmelli, R.; Ruberti, R.; Menna, M. Chemical Investigation of the Indonesian Tunicate Polycarpa aurata and Evaluation of the Effects Against Schistosoma mansoni of the Novel Alkaloids Polyaurines A and B. Mar. Drugs 2019, 17, 278. [CrossRef]

21. Minale, L.; Riccio, R.; Sodano, G. Avarol, a novel sesquiterpenoid hydroquinone with a rearranged drimane skeleton from the sponge Dysidea avara. Tetrahedron Lett. 1974, 38, 3401-3404. [CrossRef]

22. De Rosa, S.; Minale, L.; Riccio, R.; Sodano, G. The absolute configuration of avarol, a rearranged sesquiterpenoid hydroquinone from a marine sponge. J. Chem. Soc. Perkins Trans. 1 1976, 13, 1408-1414. [CrossRef]

23. Cozzolino, R.; De Giulio, A.; De Rosa, S.; Strazzullo, G.; Gašić, M.J.; Sladić, D.; Zlatović, M. Biological Activities of Avarol Derivatives, 1. Amino Derivatives. J. Nat. Prod. 1990, 53, 699-702. [CrossRef]

24. Müller, W.E.G.; Zahn, R.K.; Gašić, M.J.; Dogović, N.; Maidhof, A.; Becker, C.; Diehl-Seifert, B.; Eich, E. Avarol, a cytostatically active compound from the marine sponge Dysidea avara. Comp. Biochem. Physiol. 1985, 80C, 47-52. [CrossRef]

25. Müller, W.E.G.; Maidhof, A.; Zahn, R.K.; Schröder, H.C.; Gašić, M.J.; Heidemann, D.; Bernd, A.; Kurelec, B.; Eich, E.; Seibert, G. Potent antileukemic activity of the novel cytostatic agent avarone and its analogues in vitro and in vivo. Cancer Res. 1985, 45, 4822-4826. [PubMed]

26. Müller, W.E.G.; Sladić, D.; Zahn, R.K.; Bässler, K.H.; Dogović, N.; Gerner, H.; Gašić, M.J.; Schröder, H.C. Avarol-induced DNA Strand Breakage in vitro and in Friend Erythroleukemia Cells. Cancer Res. 1987, 47, 6565-6571.

27. Ferrándiz, M.L.; Sanz, M.J.; Bustos, G.; Payá, M.; Alcaraz, M.J.; De Rosa, S. Avarol and avarone, two new anti-inflammatory agents of marine origin. Eur. J. Pharmacol. 1994, 253, 75-82. [CrossRef]

28. Belisario, M.A.; Maturo, M.; Avagnale, G.; De Rosa, S.; Scopacasa, F.; De Caterina, M. In vitro effect of avarone and avarol, a quinone/hydroquinone couple of marine origin, on platelet aggregation. Pharmacol. Toxicol. 1996, 79, 300-304. [CrossRef]

29. Lucas, R.; Giannini, C.; D’Auria, M.V.; Payá, M. Modulatory effect of bolinaquinone, a marine sesquiterpenoid, on acute and chronic inflammatory processes. J. Pharmacol. Exp. Ther. 2003, 304, 1172-1180. [CrossRef]

30. Kurelec, B.; Zahn, R.K.; Gasić, M.J.; Britvić, S.; Lucić, D.; Müller, W.E. Antimutagenic activity of the novel antileukemic agents, avarone and avarol. Mutat. Res. 1985, 144, 63-66. [CrossRef]

31. Seibert, G.; Raether, W.; Dogović, N.; Gašić, M.J.; Zahn, R.K.; Müller, W.E.G. Antibacterial and antifungal activity of avarone and avarol. Zent. Bakteriol. Hyg. 1985, 260A, 379-386. [CrossRef]

32. Sarin, P.S.; Sun, D.; Thornton, A.; Müller, W.E.G. Inhibition of replication of the etiological agent of acquired immune deficiency syndrome (human T-lymphotropic retrovirus/lymphadenopathy-associated virus) by avarol and avarone. J. Natl. Cancer Inst. 1987, 78, 663-666. 
33. Loya, S.; Hizi, A. The inhibition of human immunodeficiency virus type 1 reverse transcriptase by avarol and avarone derivatives. FEBS Lett. 1990, 269, 131-134. [CrossRef]

34. De Rosa, S. Marine Natural Products: Analysis, Structure Elucidation, Bio-Activity and Potential Use as Drug. In Natural Products in the New Millenium: Prospects and Industrial Applications; Rauter, A.P., Palma, F.B., Justino, J., Araújo, M.E., Dos Santos, S.P., Eds.; Kluwer: Dordrecht, The Netherlands, 2002; pp. 441-461.

35. Belisario, M.A.; Maturo, M.; Pecce, R.; De Rosa, S.; Villani, G.R. Effect of avarol and avarone on in vitro-induced microsomal lipid peroxidation. Toxicology 1992, 72, 221-233. [CrossRef]

36. Amigó, M.; Payá, M.; Braza-Boills, A.; De Rosa, S.; Terencio, M.C. Avarol inhibits TNF-alpha generation and NF-kB activation in human cells and in animal models. Life Sci. 2008, 82, 256-264. [CrossRef]

37. Tsoukatou, M.; Maréchal, J.P.; Hellio, C.; Novaković, I.; Tufegdzic, S.; Sladić, D.; Gašić, M.J.; Clare, A.S.; Vagias, C.; Roussis, V. Evaluation of the Activity of the Sponge Metabolites Avarol and Avarone and their Synthetic Derivatives Against Fouling Micro- and Macroorganisms. Molecules 2007, 12, 1022-1034. [CrossRef] [PubMed]

38. Vilipic, J.; Novakovic, I.; Stanojkovic, T.; Matic, I.; Segan, D.; Kljajic, Z.; Sladic, D. Synthesis and biological activity of amino acid derivatives of avarone and its model compound. Bioorg. Med. Chem. 2015, 23, 6930-6942. [CrossRef]

39. Bozic, T.; Novakovic, I.; Gasic, M.J.; Juranic, Z.; Stanojkovic, T.; Tufegdzic, S.; Kljajic, Z.; Sladic, D. Synthesis and biological activity of derivatives of the marine quinone avarone. Eur. J. Med.Chem. 2010, 5, 923-929. [CrossRef]

40. Diaz-Marrero, A.R.; Austin, P.; Van Soest, R.; Matainaho, T.; Roskelley, C.D.; Roberge, M.; Andersen, R.J. Avinosol, a meroterpenoid-nucleoside conjugate with antiinvasion activity isolated from the marine sponge Dysidea sp. Org. Lett. 2006, 8, 3749-3752. [CrossRef]

41. De Giulio, A.; De Rosa, S.; Strazzullo, G.; Diliberto, L.; Obino, P.; Marongiu, M.E.; Pani, A.; La Colla, P. Synthesis and evaluation of cytostatic and antiviral activities of $3^{\prime}$ and $4^{\prime}$-avarone derivatives. Antivir. Chem. Chemother. 1991, 2, 223-227. [CrossRef]

42. Butterworth, A.S.; Skinner-Adams, T.S.; Gardiner, D.L.; Trenholme, K.R. Plasmodium falciparum gametocytes: With a view to a kill. Parasitology 2013, 140, 1718-1734. [CrossRef]

43. Pérez-Pertejo, Y.; Escudero-Martínez, J.M.; Reguera, R.M.; Balaña-Fouce, R.; García, P.A.; Jambrina, P.G.; San Feliciano, A.; Castro, M.-Á. Antileishmanial activity of terpenylquinones on Leishmania infantum and their effects on Leishmania topoisomerase IB. Int. J. Parasitol. Drugs Drug Resist. 2019, 11, 70-79. [CrossRef]

44. Katsuno, K.; Burrows, J.N.; Duncan, K.; van Huijsduijnen, R.H.; Kaneko, T.; Kita, K.; Slingsby, B.T. Hit and lead criteria in drug discovery for infectious diseases of the developing world. Nat. Rev. Drug Discov. 2015, 14, 751-758. [CrossRef] [PubMed]

45. Skelly, P.J.; Shoemaker, C.B. Induction cues for tegument formation during the transformation of Schistosoma mansoni cercariae. Int. J. Parasitol. 2000, 30, 625-631. [CrossRef]

46. McManus, D.P.; Dunne, D.W.; Sacko, M.; Utzinger, J.; Vennervald, B.J.; Zhou, X.-N. Schistosomiasis. Nat. Rev. Dis. Primers 2018, 4, 13. [CrossRef] [PubMed]

47. Michaels, R.M.; Prata, A. Evolution and characteristics of Schistosoma mansoni eggs laid in vitro. J. Parasitol. 1968, 54, 921-930. [CrossRef]

48. Ewig, C.S.; Berry, R.; Dinur, U.; Hill, J.R.; Hwang, M.J.; Li, H.; Liang, C.; Maple, J.; Peng, Z.; Stockfisch, T.P.; et al. Derivation of class II force fields. VIII. Derivation of a general quantum mechanical force field for organic compounds. J. Comput. Chem. 2001, 22, 1782-1800. [CrossRef]

49. Cossi, M.; Rega, N.; Scalmani, G.; Barone, V. Energies, structures, and electronic properties of molecules in solution with the C-PCM solvation model. J. Comp. Chem. 2003, 24, 669-681. [CrossRef]

50. Lipinski, C.A.; Lombardo, F.; Dominy, B.W.; Feeney, P.J. Experimental and computational approaches to estimate solubility and permeability in drug discovery and development settings. Adv. Drug Deliv. Rev. 2001, 46, 3-26. [CrossRef]

51. Van Hellemond, J.J.; Retra, K.; Brouwers, J.F.; van Balkom, B.W.; Yazdanbakhsh, M.; Shoemaker, C.B.; Tielens, A.G. Functions of the tegument of schistosomes: Clues from the proteome and lipidome. Int. J. Parasitol. 2006, 236, 691-699. [CrossRef]

52. Skelly, P.J.; Wilson, R.A. Making sense of the schistosome surface. Adv. Parasitol. 2006, 65, 185-284.

53. Sunter, J.; Gull, K. Shape, form, function and Leishmania pathogenicity: From textbook descriptions to biological understanding. Open Biol. 2017, 7, 170165. [CrossRef] 
54. D'Alessandro, S.; Silvestrini, F.; Dechering, K.; Corbett, Y.; Parapini, S.; Timmerman, M.; Galastri, L.; Basilico, N.; Sauerwein, R.; Alano, P.; et al. A Plasmodium falciparum screening assay for anti-gametocyte drugs based on parasite lactate dehydrogenase detection. J. Antimicrob. Chemother. 2013, 68, 2048-2058. [CrossRef] [PubMed]

55. D'Alessandro, S.; Camarda, G.; Corbett, Y.; Siciliano, G.; Parapini, S.; Cevenini, L.; Michelini, E.; Roda, A.; Leroy, D.; Taramelli, D.; et al. A chemical susceptibility profile of the Plasmodium falciparum transmission stages by complementary cell-based gametocyte assays. J. Antimicrob. Chemother. 2016, 71, 1148-1158. [CrossRef] [PubMed]

56. Lalli, C.; Guidi, A.; Gennari, N.; Altamura, S.; Bresciani, A.; Ruberti, G. Development and validation of a luminescence-based, medium-throughput assay for drug screening in Schistosoma mansoni. PLoS Negl. Trop. Dis. 2015, 9, e0003484. [CrossRef] [PubMed]

57. Guidi, A.; Lalli, C.; Gimmelli, R.; Nizi, E.; Andreini, M.; Gennari, N.; Saccoccia, F.; Harper, S.; Bresciani, A.; Ruberti, G. Discovery by organism based high-throughput screening of new multi-stage compounds affecting Schistosoma mansoni viability, egg formation and production. PLoS Negl. Trop. Dis. 2017, 11, e0005994. [CrossRef]

58. Fletcher, R. Unconstrained optimization. In Practical Methods of Optimization, 1st ed.; John Wiley \& Sons Ltd.: New York, NY, USA, 1980; Volume 1, pp. 1-128. ISBN 978-0471277118.

59. Gaussian 09 Citation. Available online: https://gaussian.com/g09citation/ (accessed on 13 February 2020).

60. Becke, D. Density-functional thermochemistry. III. The role of exact exchange. J. Chem. Phys. 1993, 98, 5648-5652. [CrossRef]

61. Lee, C.; Yang, W.; Parr, R.G. Development of the Colle-Salvetti correlation-energy formula into a functional of the electron density. Phys. Rev. B Condens. Matter Mater. Phys. 1988, 37, 785-789. [CrossRef]

62. Reed, E.; Weinstock, R.B.; Weinhold, F. Natural Population Analysis. J. Chem. Phys. 1985, 83, 735-746. [CrossRef]

63. Li, J.; Fisher, C.L.; Chen, J.L.; Bashford, D.; Noodleman, L. Calculation of Redox Potentials and pKa Values of Hydrated Transition Metal Cations by a Combined Density Functional and Continuum Dielectric Theory. Inorg. Chem. 1996, 35, 4694-4702. [CrossRef]

64. Moens, J.; Geerlings, P.; Roos, G. A Conceptual DFT Approach for the Evaluation and Interpretation of Redox Potentials. Chem. Eur. J. 2007, 13, 8174-8184. [CrossRef]

65. Koopmans, T. Ordering of Wave Functions and Eigenenergies to the Individual Electrons of an Atom. Physica 1933, 1, 104-113. [CrossRef]

66. Aiello, A.; Fattorusso, E.; Luciano, P.; Macho, A.; Menna, M.; Muñoz, E. Antitumor effects of two novel naturally occurring terpene quinones isolated from the mediterranean ascidian Aplidium conicum. J. Med. Chem. 2005, 48, 3410-3416. [CrossRef] [PubMed]

(C) 2020 by the authors. Licensee MDPI, Basel, Switzerland. This article is an open access article distributed under the terms and conditions of the Creative Commons Attribution (CC BY) license (http://creativecommons.org/licenses/by/4.0/). 